(2) Open Access Full Text Article

REVIEW

\title{
Assessment of late-life depression via self-report measures: a review
}

This article was published in the following Dove Press journal:

Clinical Interventions in Aging

\section{Michela Balsamo \\ Fedele Cataldi \\ Leonardo Carlucci \\ Caterina Padulo \\ Beth Fairfield}

Department of Psychological, Health and Territorial Sciences, School of

Medicine and Health, University "G.

d'Annunzio" of Chieti-Pescara, Italy
Correspondence: Michela Balsamo Department of Psychological, Health and Territorial Sciences, University "G. d'Annunzio" of Chieti-Pescara via dei Vestini, 3I, Chieti 66I00, Italy

Tel +0039087I 3555309

Emailmbalsamo@unich.it

\begin{abstract}
Depression in later life is a significant and growing problem. Age-related differences in the type and severity of depressive disorders continue to be questioned and necessarily question differential methods of assessment and treatment strategies. A host of geropsychiatric measures have been developed for diagnostic purposes, for rating severity of depression, and monitoring treatment progress. This literature review includes the self-report depression measures commonly and currently used in geropsychological practice. Each of the included measures is considered according to its psychometric properties. In particular, information about reliability; convergent, divergent, and factorial validity evidence based on data from clinical and nonclinical samples of older adults; and availability of age-appropriate norms was provided along with the strengths and weaknesses of each measure. Results highlighted that in cognitively intact or mildly impaired patients over 65 years, the Geriatric Depression Scale and the Geriatric Depression Scale-15 currently seem to be the preferred instruments. The psychometric functioning of the Beck Depression Inventory-II and the Center for Epidemiological Studies Depression Scale, instead, is mixed in this population. Most importantly, this review may be a valuable resource for practicing clinicians and researchers who wish to develop state-of-the-science assessment strategies for clinical problems and make informed choices about which instruments best suit their purposes in older populations.
\end{abstract}

Keywords: depression, older adults, self-report, psychometric functioning, assessment, aging

\section{Introduction}

The words "depression" and "ubiquity" are often found in the same sentence, ${ }^{1}$ and according to the World Health Organization, ${ }^{2}$ by 2020 , depression will be the second leading cause of disease worldwide. Moreover, depression appears to increase with age, ${ }^{3,4}$ probably because of physical and mental decline and infirmity, with consequent restricted activity and low perceived sense of controlling one's own life and destiny. 5,6

\section{Background: prevalence and correlates of late-life depression}

Depression is a costly, persistent, and common debilitating condition among older adults. $^{7-12}$

Specifically, $52 \%$ of cases have their first onset of depression at age 60 or older. ${ }^{13}$ According to some epidemiological studies, the point prevalence of major depression is $4.6 \%-9.3 \%$ in patients over 75 years and increases to $27 \%$ in those over 85 years. ${ }^{14,15}$ However, prevalence estimates vary broadly depending on the definition, method of assessment, and particular sample utilized. 
Most importantly, late-life depression that is undiagnosed or untreated may lead to a higher risk of morbidity; a decrease in cognitive, physical, and social functioning; general selfneglect and an increase of the dependence by the others. ${ }^{16,17}$ Because depression appears to compromise the functioning of the immune system, it might impair the body's resistance to disease and predict a more severe or fatal course of illness. In addition, more than other forms of psychological distress, late-life depression reduces survival: according to several studies, severely depressed older adult patients die at a rate significantly higher than others (controlling for sex, preexisting chronic health problems, socioeconomic status, and fitness). ${ }^{3,16-24}$

A small part of excess mortality among the depressed is due to suicide, which has its highest rates among the older adults, ${ }^{25,29-31}$ with estimates from 6 to 83 per 100,000 for men and from 7.4 to 31.4 for women among adults aged $65+$ years in European countries, ${ }^{26}$ and these estimates increase if accompanied by poor health and social isolation. ${ }^{27,28}$ Particularly, if depression is caused by or accompanied by poor health and social isolation, it readily leads to hopelessness and suicidality. ${ }^{27,28}$ Finally, up to $50 \%$ of patients with Alzheimer's disease develop a depressive disorder, although it is unclear whether depression is a causative or risk factor or a prodromal symptom of Alzheimer's. ${ }^{32,33}$ In sum, examining diagnostic and clinical characteristics of late-life depression is of fundamental importance, given its severe and wideranging implications.

\section{Specific diagnostic and clinical features of the late-life depression}

The validity of existing criteria for geriatric depressive disorders (eg, Diagnostic and Statistical Manual of Mental Disorders-Fifth edition, DSM5; APA, 2013) continues to be questioned. Existing data suggest that there are qualitative differences in the clinical presentation of depression in younger and older adults, and that the different presentations of depression in older adults are not fully assessed by the current measures of depression..$^{8,17,34}$ Accordingly, late-life depression presents unique characteristics to researchers and clinicians interested in the nature, assessment, and treatment of depression. ${ }^{35,36}$ Among these:

1. The overlap between dementia and depression in the older adults. Subjective experiences of cognitive impairment and memory loss are typical symptoms of depression in the older adults mistaken for dementia. ${ }^{37}$ Psychomotor retardation and passive refusal to respond appropriately to cognitive tests are typical symptoms of "pseudodementia," that is, depression mistaken for dementia. $3,38,39$

2. The overlap with somatic symptoms. Somatic symptoms associated with depression tend to be emphasized more by older depressed patients, while feelings of dysphoria or sadness are reported less. ${ }^{40}$ At the same time, it is necessary to underline that late-life depression often occurs in the context of coexisting medical problems (such as neurological, arthritic, and endocrine diseases, as well as the side effects of medications such as tranquilizers, neuroleptics, or drugs for hypertension) and increased use of medical services. ${ }^{41}$

3. The relationship between depression and anxiety. As anxiety typically precedes depression in older adults, ${ }^{42-44}$ as well as in younger adults, a thorough examination of the comorbidity of anxiety and depression and the consequences of that comorbidity is warranted. Estimates of the prevalence of anxiety disorders in older adults with depression are as high as 50\%, ${ }^{45,46}$ while prevalence estimates of depression in older adults with anxiety disorders range from $25 \%$ to more than $80 \%{ }^{47}$ An overlap between these two disorders is a critical issue in terms of both adequate assessment and appropriate treatment, and recognition of comorbidity is critical to solid case formulation and predicting treatment outcomes. Indeed, comorbidity generally predicts a poorer treatment response for patients with depression and is also associated with greater psychological impairment. ${ }^{42}$

4. Underrecognition of depressive symptoms. Older adults are significantly less likely 1) to verbally express their moods $;^{7}$ 2) to recognize depression symptoms (anhedonia, loss of interest, low mood) that they attribute to normal aging process, ${ }^{48-50} 3$ ) to endorse cognitive-affective symptoms of depression, including loss of pleasure, dysphoria, and worthlessness; ${ }^{17,51} 4$ ) to declare a decline in sexual functioning, because they are offended by questions about sexuality.

Because late-life depression has a different manner of presentation, several geriatric-specific variants of depression have been proposed. One of these, the "depletion syndrome," is characterized by hopelessness, loss of appetite, thoughts of death, and lack of interest. ${ }^{52,53}$ Another variant is the "depression-executive dysfunction syndrome." ${ }^{54}$ In this syndrome, cognitive performance is typically impaired on measures of verbal fluency, naming and initiation/perseveration, and psychomotor retardation and anhedonia are included, but vegetative symptoms, agitation and guilt 
are less severe than in other types of depression. Test measures were found to underestimate the depletion syndrome, although they generally inflated the extent to which depression was found in older adults. Thus, the measures currently used may underestimate depression in older adults because they do not measure the most common subtype of geriatric depression. ${ }^{55}$

\section{Assessing late-life depression via self- report measures}

Self-report measures are widely employed to assess the incidence and severity of depressive symptoms in both epidemiological studies and in clinical settings with older adults. ${ }^{56}$ Typically, this method of assessment is conducted using a paper-and-pencil format, although the questionnaire can also be completed via computer. Depending on the questionnaire, this method is relatively brief, taking as few as 10 minutes, and patients may complete the questionnaire outside medical context.

Nonetheless, the self-report method for assessing depression has its limitations, including vulnerability to misinterpretation and response biases. ${ }^{57}$ In addition, self-report questionnaires may not be sufficient as the sole approach for measuring suicidal ideation, and are not well suited for individuals who have difficulties with reality testing, have a thought disorder, or have such severe symptoms that they are unable to concentrate. Furthermore, it can be tempting to use the cutoff score of a self-report inventory as the single means of deriving a diagnosis, a practice that should be avoided. ${ }^{1}$ Indeed, respondents scoring above the established cutoff level should be interviewed to assess the depressive disorders criteria found in the DSM $5,{ }^{58}$ such as degree of impairment, duration of symptoms, and comorbid psychiatric disorders. ${ }^{59}$

Finally, it must be emphasized that only clinical interviews and observation are capable of capturing information such as nonverbal aspects, which are essential for diagnosis. ${ }^{60-62}$ For example, negative emotions and social behaviors are indicators of severity of depression and relevant predictors of its clinical remission ${ }^{63-66}$ that are beyond the control and awareness of the patient answering a questionnaire. ${ }^{67,68}$ In addition, assessing depression symptoms in older adults via self-report measures can be more difficult than in younger cohorts due to the number of specific factors mentioned above that characterize this disorder in late-life..$^{9,10,59,69-71}$ For instance, although questionnaires can be quickly completed and scored, other time-intensive, interviewer-administered measures may be necessary when patients are cognitively impaired.

\section{Aim of this review}

Successful treatment depends on effective assessment. ${ }^{72}$ Accordingly, this literature review intends to describe the most commonly and currently used depression self-report measures validated for use with older adults. To this end, we present information addressing the psychometric properties (eg, normative data, reliability, and validity, as well as sensitivity and specificity diagnostic statistics), to provide practical assessment recommendations for clinicians and researchers and to aid them in their choice of measure.

\section{Method}

A major attempt was made to identify all relevant instruments for a possible inclusion in this review. This entailed searching professional peer-reviewed journals, comprehensive literature reviews, test manuals, and multiple computer searches. Pertinent studies were identified through keyword searches in scientific databases that target the majority of published literature in the social and medical fields (eg, Google Scholar, Wiley Online Library, PubMed, Web of Knowledge and PsycINFO). Search terms (or word stems) consisted of ("depression*" [Title/Abstract] OR "depression disorder*" [Title/Abstract] OR “assessment*" [Title/Abstract] OR "psychometric properties*" [Title/Abstract] OR "mood disorder*" [Title/ Abstract]) AND ("older adults*" [Title/Abstract] OR "older adults" [Title/Abstract] OR "geriatric population" [Title/ Abstract]); where * denotes any wildcard. Manual searches of relevant peer-reviewed journals (eg, "Psychology and aging," "International Journal of Geriatric Psychiatry," "The Gerontologist," "Psychology and Aging," "Clinical Gerontologist," "Journal of Gerontologist," "International Psychogeriatrics") were also conducted. The reference sections of the identified manuscripts were screened for additional studies. Studies considered in the current review met the following inclusion criteria: 1) the study reports original research investigating psychometric properties (ie, reliability, factorial, convergent, and divergent validity); 2) the most currently used self-report measures have been taken into consideration; 3) study participants were included as both clinical and nonclinical groups; and 4) the study was published in English.

Final selection was based on the following criteria: the self-report measure must 1) assess depressive symptoms; 2) be administered by self-report; 3) be set in adults aged 65 years and above; 4) be characterized by some known psychometric properties.

Measures typically used to evaluate diagnostic criteria or features of specific anxiety disorders, such as mood disorder, major depressive episode, and others (eg, guilt, corumination) 


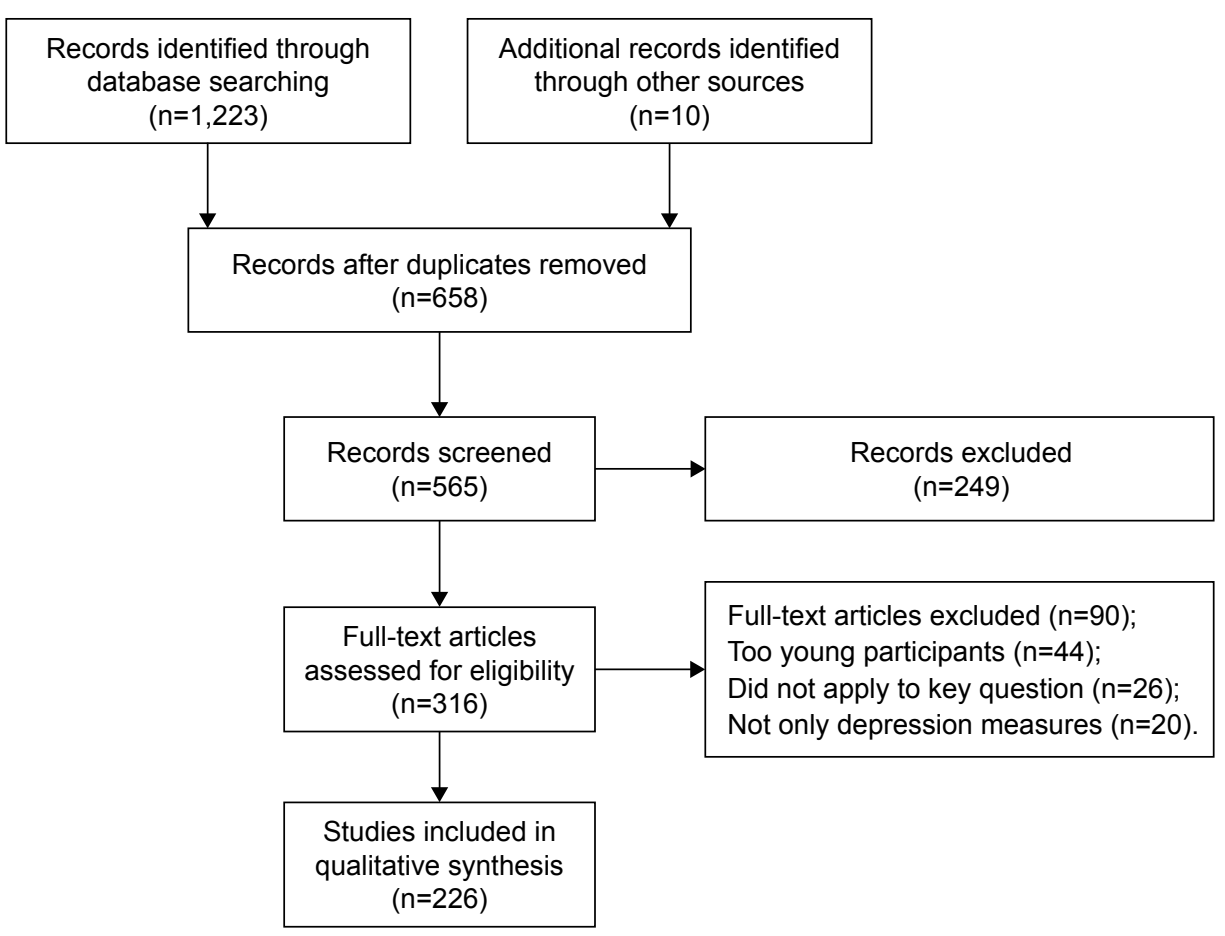

Figure I Flowchart of review procedure.

were excluded. ${ }^{74-76}$ Figure 1 provides a synthetic flow diagram of the multistep selection procedure adopted in this review. ${ }^{77}$

Using these criteria, the most commonly used measures to evaluate depression in older adults included the Zung SelfRating Depression Scale; ${ }^{78}$ the Geriatric Depression Scale, ${ }^{79-81}$ the Geriatric Depression Scale - short form; ${ }^{82}$ the Beck Depression Inventory - II ${ }^{83}$ and the Center for Epidemiologic Studies Depression Scale, ${ }^{84}$ together with its short forms of $11,{ }^{85} 10,{ }^{86}$ and 8 items. ${ }^{87}$ To facilitate readability, we adopted a standard outline that is used to describe each instrument. We first present an overview of the structure and the items of the instrument, including response format, norms and the scoring procedure, are described. We also included a brief description of the specific population for which the test was developed. We then reported relevant findings regarding internal consistency and test-retest reliability, and various validity estimates if available are reported. Clinical utility was rated as "high" if a given instrument was frequently used in clinical settings, or "limited" if if not or if clinicians found that the time or cost associated with the measures was somewhat prohibitive. Table 1 presents a summary of the characteristics for each measure.

\section{Results}

\section{Zung Self-Rating Depression Scale (SDS)}

\section{General characteristics}

The Zung SDS is a self-report measure of depressive symptoms, ${ }^{78}$ composed of 20 items that investigate pervasive affect, physiological and psychological aspects related to pervasive affect. It was specifically designed for patients with a primary depression diagnosis, and targeting a wide range of related symptoms. Categories of items were selected based on factor analyses found in the literature that provided the most common types of symptoms associated with depression. Specific items within these categories were then developed using illustrative verbatim records taken from sentences from patient interviews of patients that were the most representative of the symptoms involved. ${ }^{78}$ Of the 20 items, 10 are worded positively (eg, "I feel hopeful about the future") and 10 negatively (eg, "I feel downhearted and blue"). Each item is rated on a four-point scale with anchor points referring to the amount of time the symptom is currently experienced. These range from "a little of the time" to "most of the time." The total score is obtained by summing the ratings from the 20 items for a total score ranging from 20 to 80, with higher scores indicate higher levels of depression. An index score can also be obtained by dividing the obtained raw score by the maximum possible score of 80 and expressed as a decimal. ${ }^{78}$ The SDS was administered to a clinical sample of $n=31$ patients with primary diagnosis of depressive disorders, 25 nondepressed patients disorders, and to a control sample of 100 subjects. Mean scores were: 0.74 for of the depressed group, 0.53 for the group with other psychiatric disorders, and 0.33 for the control sample. In several later studies, an SDS cutoff score of 46 achieved 
$80 \%$ sensitivity and $85 \%$ specificity. ${ }^{79}$ Sensitivity was equal to $76 \%$ and specificity $96 \%$ for a recommended cutoff of 45 among 40 healthy oldest old (mean age of 80 years). ${ }^{88}$ An SDS total score greater than or equal to 50 achieved $83 \%$ sensitivity and $81 \%$ specificity, while a score greater than or equal to 60 achieved $67 \%$ sensitivity and $92 \%$ specificity in a clinical sample of 40 chronic pain patients, ranging in age from 21 to 77 years. ${ }^{89}$ On the basis of these studies, the following norms and interpretative guidelines were established: below 50= normal; 50 $-59=$ mild depression; $60-69=$ moderate to marked depression; $\geq 70=$ severe depression. The SDS takes approximately 5-10 minutes to complete..$^{90}$

\section{Reliability}

In the study by Gabrys and Peters, ${ }^{91}$ split-half reliability was high, with $r=0.94$, as well as internal consistency, with $\alpha$ s of 0.88 for the clinical sample $(n=369)$ and 0.93 for controls $(\mathrm{n}=218)$. Mean item-correlations were $r=0.82$ and $r=0.85$, respectively. ${ }^{91}$ In the validation study of validation of the Geriatric Depression Scale (GDS), ${ }^{79}$ Cronbach's $\alpha$ was 0.87 , and the split-half reliability coefficient was 0.81 in a sample divided into a clinical sample $(n=60)$ and a control sample $(\mathrm{n}=40) .{ }^{79}$ In a study by Knight et al, ${ }^{92}$ the Cronbach $\alpha$ was 0.79 in a nonclinical sample, ranging in age from 16 to 89 years. In a study by Agrell and Dehlin, ${ }^{88}$ reliability of the SDS was high, with Cronbach's $\alpha$ equal to 0.83 in 40 patients who had previously had a stroke, ranging in age from 61 to 93 years. Also Dunn and Sacco also reported an $\alpha$ of 0.84 in a nonclinical sample of 439 older adults (mean age $=74$ years) ${ }^{93}$ In the study by De Jonghe and Baneke, ${ }^{94}$ Cronbach's $\alpha$ of the SDS was 0.82 and split-half coefficient was 0.79 , in a clinical sample ranging from 19 to 59 years. Finally, in a study by Dugan et al, ${ }^{95}$ Cronbach's $\alpha$ of the SDS was 0.84 in a sample of 1,109 ambulatory cancer patients ranging from 18 to 80 years and over. Overall, the internal reliability of the SDS appears to be moderate to high, ranging between 0.79 and 0.93 . This is most apparent among the oldest old. ${ }^{96,97}$ Older adults tend to score higher than younger adults, possibly due to the somatic items included in the scale. ${ }^{98}$

\section{Convergent and discriminant validity}

Zung et al (1965) found significant and positive correlations between SDS and Minnesota Multiphasic Personality Inventory (MMPI) several scales in 152 patients. ${ }^{99,100}$ In particular, correlation of the SDS was 0.70 with D (depression) scale, 0.68 with the Pt (psychastenia) scale, and 0.13 with the Ma (hypomania), as expected ( $P$ not reported). In a subsequent study by Zung, ${ }^{101}$ in a clinical sample of 159 subjects, the correlation between the SDS and the MMPI D Scale T-scores was 0.59 , due to the higher percentage of younger patients. In another study by Zung, ${ }^{102}$ which illustrated the development of the Depression Status Inventory (DSI), ${ }^{102}$ the correlation between the SDS and the DSI was $r=0.87(P<0.01)$ in a clinical sample of 225 patients. Biggs et al found correlation of $r=0.80(P<0.001)$ between the SDS and the Hamilton Rating Scale for Depression (HRS) in a clinical sample. ${ }^{103,104}$ In a study by Yesavage et al SDS correlated $r=0.84(P<0.001)$ with the GDS, and $r=0.80(P<0.001)$ with the HRS in a clinical and control groups. ${ }^{79}$ In a study by Turner and Romano, ${ }^{89}$ correlation of the SDS was $r=0.76(P<0.01)$. with the MMPI D scale, $r=0.86(P<0.01)$ with the Beck Depression Inventory (BDI) ${ }^{105}$ and $r=0.85(P<0.01)$ with the short form of the BDI (BDI-SF). ${ }^{106,107}$ A lower correlation, $r=0.54(P<0.001)$ was found between the SDS and the BDI in a separate study. ${ }^{108}$ In a study by Agrell and Dehlin,${ }^{88}$ correlation of the SDS was $r=0.88(P<0.001)$ with GDS, $r=0.81(P<0.001)$ with Center for Epidemiologic Studies Depression Scale, $r=0.70(P<0.001)$ with HRS, $r=0.82(P<0.001)$ with Comprehensive Psychopathological Rating Scale-Depression (CPRS-D) in a nonclinical sample. ${ }^{109}$ The only low correlation value $(r=0.32 ; P<0.02)$ was found with the Cornell Scale (CS) ${ }^{88,110}$ In another study, ${ }^{93}$ the correlation of the SDS was $r=0.59(P<0.001)$ with the GDS, and $r=0.57$ $(P<0.001)$ with the Depression Symptom Checklist (DSC) in a nonclinical sample. ${ }^{111}$ Regarding the discriminative validity (that is the extent to which scores on a measure distinguish between groups known or suspected to differ on the construct assessed by the target measure), examination of mean scores indicated that the SDS adequately discriminated among nondepressed and depressed patients $(t=30.85 ; P<0.001) .{ }^{91}$ A cutoff score of 40 (index score $=0.50)$ was established to examine predictive validity. Of the nondepressed clinical group, 23\% scored above the cutoff, yielding a successful prediction rate of $77 \%$. Of the depressed clinical group, only $8 \%$ scored below the cutoff, yielding a successful prediction rate of $92 \%{ }^{91}$

\section{Factorial structure}

In an initial factorial analysis of the SDS in a nonclinical sample, four factors emerged, with the first identified as "loss of self-esteem," and the remaining three factors were more focused on biological symptoms. ${ }^{101}$ The four-factor structure, accounting for more than $50 \%$ of the total variance, was also confirmed by Steuer in a clinical sample of 60 depressed older persons, ${ }^{112}$ and by Passik et al ("Cognitive"; "Manifest 
Table I Elder-specific self-report measures of depression

\begin{tabular}{|c|c|c|c|c|c|c|}
\hline Name & Year & Item & $\begin{array}{l}\text { Response } \\
\text { type }\end{array}$ & Subscale $^{a}$ & Sample & Language \\
\hline SDS & 1965 & 20 & $\begin{array}{l}\text { Likert (4-point) } \\
\text { [I "a little of the } \\
\text { time" to } 4 \text { "most } \\
\text { of the time"] }\end{array}$ & One general factor & $\begin{array}{l}\mathrm{N}=3 \mathrm{I} \\
\text { Patients with depressive disorders } \\
\mathrm{N}=25 \\
\text { Nondepressed patients } \\
\mathrm{N}=100 \\
\text { Nonclinical group }\end{array}$ & USA $^{78}$ \\
\hline GDS & 1983 & 30 & $\begin{array}{l}\text { Dichotomous } \\
\text { (yes/no) }\end{array}$ & One general factor & $\begin{array}{l}\mathrm{N}=0.47 \text { [ } 55+\text { years old }] \\
\text { Nonclinical elderly living in the community } \\
\mathrm{N}=40 \text { [55+ years old] } \\
\text { Nonclinical elderly people recruited at local } \\
\text { senior centers and housing projects } \\
\mathrm{N}=60 \text { [55+ years old] } \\
\text { Patients with depressive disorders } \\
\mathrm{N}=193 \text { [ } 17-55 \text { years] } \\
\text { Nonclinical sample }\end{array}$ & USA $^{79}$ \\
\hline GDS-SF & 1986 & 15 & $\begin{array}{l}\text { Dichotomous } \\
\text { (yes/no) }\end{array}$ & One general factor & $\begin{array}{l}\mathrm{N}=35 \\
\text { Mixed sample }\end{array}$ & USA $^{82}$ \\
\hline BDI-II & 1996 & 21 & $\begin{array}{l}\text { Guttman } \\
\text { (4-point) } \\
\text { [0-3 representing } \\
\text { ascending levels of } \\
\text { severity] }\end{array}$ & One general factor & $\begin{array}{l}\mathrm{N}=500 \\
\text { Psychiatric outpatient sample } \\
\mathrm{N}=120 \\
\text { College students sample }\end{array}$ & $\begin{array}{l}\text { USA }^{83} \\
\text { Puerto Rico } \\
178\end{array}$ \\
\hline CES-D-20 & 1977 & 20 & $\begin{array}{l}\text { Likert } \\
\text { (4-point) } \\
\text { [0 "rarely or none } \\
\text { of the time" to } 3 \\
\text { "most or all of the } \\
\text { time"] }\end{array}$ & $\begin{array}{l}\text { Depressed affect } \\
\text { ( } 7 \text { items) } \\
\text { Positive affect } \\
\text { (4 items) } \\
\text { Somatic and Retarded } \\
\text { Activity } \\
\text { (7 items) } \\
\text { Interpersonal relations } \\
\text { ( } 2 \text { items) }\end{array}$ & $\begin{array}{l}\mathrm{N}=2,514[18+\text { years old] } \\
\text { Nonclinical participants living in Kansas and } \\
\text { Washington County } \\
\mathrm{N}=1,060[18+\text { years old] } \\
\text { Nonclinical participants living in Washington } \\
\text { County } \\
\mathrm{N}=1,422 \text { [ } 18+\text { years old] } \\
\text { Nonclinical participants living in Kansans and } \\
\text { Washington County } \\
\mathrm{N}=419 \\
\text { Nonclinical participants recruited by email } \\
\mathrm{N}=70 \\
\text { Psychiatric patients }\end{array}$ & $\begin{array}{l}\text { USA }^{84} \\
\text { The } \\
\text { Netherlands } \\
\text { India }^{213} \\
\text { China }^{224}\end{array}$ \\
\hline
\end{tabular}




\begin{tabular}{|c|c|c|c|c|}
\hline Reliability $^{\mathrm{b}}$ & Test-retest & Cutoff & Validity & Factorial study \\
\hline $0.79-0.93^{79,88,91-95}$ & & $\begin{array}{l}\geq 46 \\
\text { Sensitivity }=80 \% \\
\text { Specificity }=85 \%^{79} \\
\geq 45 \\
\text { Sensitivity }=76 \% \\
\text { Specificity }=96 \%^{88} \\
\geq 50 \\
\text { Sensitivity }=83 \% \\
\text { Specificity }=81 \%^{89} \\
\geq 60 \\
\text { Sensitivity }=67 \% \\
\text { Specificity }=92 \%{ }^{89}\end{array}$ & $\begin{array}{l}\text { Convergent } \\
\text { MMPI D (depression) } r=0.59-0.7989,99,101 \\
\text { GDS } r=0.59-0.88^{79,88,93} \\
\text { DSI } r=0.87^{102} \\
\text { HRS-D } r=0.80^{79,103} \\
\text { BDI } r=0.85-0.86^{89} \\
\text { CES-D } r=0.81 \text {; CPRS-D } r=0.82 ; \text { CS } \\
r=0.32^{88} \\
\text { DSC } r=0.57^{93} \\
\text { Discriminant } \\
\text { MMPI Pt (psychastenia) } r=0.68 ; \text { Ma } \\
\text { (hypomania) } r=0.13^{99}\end{array}$ & $\begin{array}{l}\text { Three-factor structure }{ }^{1 / 4} \\
\text { Four-factor } \\
\text { structure }^{|0|,|12,1| 3,|1| 5}\end{array}$ \\
\hline $0.69-0.99^{79,88,93, \mid 19,121-127}$ & $0.85-0.94^{79,122}$ & $\begin{array}{l}\geq 11-16=\text { moderate depression }^{79} \\
\geq 17-30=\text { severe depression }^{17,120}\end{array}$ & $\begin{array}{l}\text { Convergent } \\
\text { SDS } r=0.84-0.88^{79,124} \\
\text { HRS-D } r=0.77-0.83^{79,124} \\
\text { DSC } r=0.57^{93} \\
\text { CES-D } r=0.82 ; \text { CPRS-D } r=0.86 ; \text { BDI } \\
r=0.78 ; \text { STAI-T } r=0.47 ; \text { QOLI } r=0.49^{124} \\
\text { CS } r=0.77^{88}\end{array}$ & $\begin{array}{l}\text { Three-factor } \\
\text { structure }^{142,144} \\
\text { Five-factor structure }^{|14|, 143} \\
\text { Six-factor structure }\end{array}$ \\
\hline $0.75-0.90^{10,154-156}$ & $0.58^{156}$ & $\begin{array}{l}\geq 4-6=\text { moderate/severe } \\
\text { depression } 152\end{array}$ & $\begin{array}{l}\text { Convergent } \\
\text { GDS } r=0.60-\left.0.9\right|^{148} \\
\text { MADRS } r=0.78^{158}\end{array}$ & $\begin{array}{l}\text { One-factor solution in } \\
\text { depressed older adults }{ }^{160} \\
\text { Two-factor solution } 156,160 \\
\text { Five-factor solution } \\
{ }^{155}\end{array}$ \\
\hline $0.76-0.93^{83,175-183}$ & $0.93^{83}$ & $\begin{array}{l}\geq 0-13=\text { minimal depression } \\
\geq 14-19=\text { mild depression } \\
\geq 20-28=\text { moderate depression } \\
\geq 29-63=\text { severe depression } \\
\geq 16=\text { depressive disorders }^{174}\end{array}$ & $\begin{array}{l}\text { Convergent } \\
\text { BDI } r=0.84-0.93 ; \text { HRS-D } r=7 \text { I; BHS } \\
r=0.68 ; \text { BSI } r=0.37^{83} \text { CES-D } r=0.69 ; \\
\text { CATI } r=0.66 ; \text { CATI Anxiety } r=0.60 \text {; } \\
\text { PSS } r=0.64,{ }^{177} \\
\text { GDS } r=\left.0.7\right|^{180} \\
\text { OAS } r=0.45^{181,272} \\
\text { Discriminant } \\
\text { SPWB } r=-0.60, \text { Subjective Health } \\
r=-0.27^{177} \\
\text { Anxiety subscale SCL-90-R } r=\left.0.7\right|^{181}\end{array}$ & $\begin{array}{l}\text { Two-factor structure } e^{83,181} \\
\text { Four-factor structure }{ }^{178}\end{array}$ \\
\hline $\begin{array}{l}0.86-0.90 \text { for the patient } \\
\text { sample } \\
0.72,84,212 \\
\text { sample }^{22,71,84,177,203,207,220-223, c}\end{array}$ & - & $\begin{array}{l}\text { Two-stage approach: } \\
\geq 15-16=\text { severe depression plus } \\
\geq 4 \text { on the depressed affect } \\
\text { subscale }^{212}\end{array}$ & $\begin{array}{l}\text { Convergent } \\
\text { BDI-II } r=0.69-0.75^{177,231} \\
\text { HADS-D } r=0.50^{221} \\
\text { GDS } r=0.82 ; \text { HRS } r=0.74 ; \text { CPRS-D } \\
r=0.83 ; \text { SDS } r=0.81^{88} \\
\text { MASQ } r=0.75 ; \text { MASQ-AD } r=0.72^{231} \\
\text { Discriminant } \\
\text { PSWQ } r=0.36^{234} \\
\text { STICSA-T } r=0.59 ; \text { TICSA-S } r=0.47 \text {; } \\
\text { TICSA-C } r=0.61 ; \\
\text { STAI-T } r=0.70^{231}\end{array}$ & Four-factor structure ${ }^{222}$ \\
\hline
\end{tabular}

(Continued) 
Table I (Continued)

\begin{tabular}{|c|c|c|c|c|c|c|}
\hline Name & Year & Item & $\begin{array}{l}\text { Response } \\
\text { type }\end{array}$ & Subscale $^{a}$ & Sample & Language \\
\hline CES-D-I I & 1993 & II & $\begin{array}{l}\text { Likert } \\
\text { (3-point) } \\
\text { [0 "hardly ever or } \\
\text { never" to } 2 \text { "much } \\
\text { or most of the } \\
\text { time"] }\end{array}$ & $\begin{array}{l}\text { Depressed affect } \\
\text { ( } 3 \text { items) } \\
\text { Positive affect } \\
\text { ( } 2 \text { items) } \\
\text { Somatic and retarded } \\
\text { activity } \\
\text { (4 items) } \\
\text { Interpersonal relations } \\
\text { ( } 2 \text { items) }\end{array}$ & & USA $^{219}$ \\
\hline CES-D- 10 & 1994 & 10 & $\begin{array}{l}\text { Likert } \\
\text { (4-point) } \\
\text { [0 “rarely or none } \\
\text { of the time" to } \\
3 \text { “most or all of } \\
\text { the time"'] }\end{array}$ & $\begin{array}{l}\text { Depressed affect } \\
\text { ( } 3 \text { items) } \\
\text { Positive affect } \\
\text { ( } 2 \text { items) } \\
\text { Somatic and retarded } \\
\text { activity } \\
\text { (5 items) }\end{array}$ & $\begin{array}{l}\mathrm{N}=\mathrm{I}, 542[65+\text { years old }] \\
\text { Healthy older adults in a large Health } \\
\text { Maintenance Organization }\end{array}$ & $\begin{array}{l}\text { USA }^{86} \\
\text { Singapore } \\
\text { South Africa } \\
\text { Taiwan }^{225} \\
\text { Thina }^{257}\end{array}$ \\
\hline CES-D-8 & 2009 & 8 & $\begin{array}{l}\text { Likert } \\
\text { (4-point) } \\
\text { [ I "rarely or none } \\
\text { of the time" to } \\
4 \text { "most or all of } \\
\text { the time"] }\end{array}$ & One general factor & $\begin{array}{l}\mathrm{N}=13,032[60+\text { years old }] \text { Healthy older } \\
\text { adults }\end{array}$ & Europe $^{217}$ \\
\hline
\end{tabular}

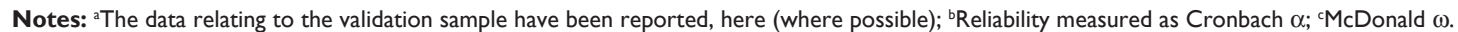

Abbreviations: SDS, Zung Self-Rating Depression Scale; GDS, Geriatric Depression Scale; GDS-SF, Geriatric Depression Scale - Short Form; BDI-II, Beck Depression Inventory-II; CES-D-20, Center for Epidemiologic Studies Depression Scale - 20 item form; CES-D-II, Center for Epidemiologic Studies Depression Scale - II item form; CES-D-I0, Center for Epidemiologic Studies of Depression - 10 item form; CES-D-8, Center for Epidemiologic Studies Depression Scale - 8 item form; MMPI D, Depression subscale of the Minnesota Multiphasic Personality Inventory; DSI, Depression Status Inventory; HRS-D, Hamilton Rating Scale for Depression; BDI, Beck Depression Inventory; CPRS-D, Comprehensive Psychopathological Rating Scale-Depression; CES-D, Center for Epidemiological Studies Depression; HDRS-R, Hamilton Depression Rating Scale revised; DSC, Depression Symptom Checklist; MMPI Pt, Psychastenia scale of the Minnesota Multiphasic Personality Inventory; MMPI Ma, Hypomania scale of the Minnesota Multiphasic Personality Inventory; STAI-T, State-Trait Anxiety Inventory - Trait subscale; QOLI, Quality of life inventory; CS, Cornell Scale for Depression in Dementia;

Depressed Mood"; "Somatic-Non-Eating"; "Somatic-Eating") in a study on nonclinical subjects between 50 and 80 years of age. ${ }^{113}$ In a meta-analysis on the factor structure of four depression questionnaires, examining 13 studies and more than 12,000 subjects, three factors were found for the SDS, and accounted for $60 \%$ of the variance. The first factor was labeled "Positive Symptoms" (nine items); the second factor was labeled as "Negative Symptoms" (eight items); and the third was a factor that other studies called "Somatic Symptoms" or "Appetite" (three item). ${ }^{114}$ Finally, in a recent study, the four-factor structure was confirmed via exploratory and confirmatory factor analysis by Romera et al. ${ }^{115}$ Factors, explaining $36.9 \%$ of total variance, were labeled "Core Depressive Factor" (eight items), "Cognitive Factor" (four items), "Anxiety Factor" (three items), and "Somatic Factor" (three items).

\section{Clinical relevance}

In the initial study, the test developer claimed that the SDS yielded a quantifiable rating of current depression in a group of hospitalized inpatients. ${ }^{78}$ Subsequently, the purpose was to demonstrate the usefulness of the SDS in an outpatient clinic, as well. ${ }^{99}$ Following these studies, several authors have supported the validity of the SDS as an effective tool for measuring depression severity during treatment and for discriminating between depressed and nondepressed patients. ${ }^{94}$ In addition, a study showed that the SDS was a valid instrument for assessing depressive 


\begin{tabular}{|c|c|c|c|c|}
\hline Reliability ${ }^{b}$ & Test-retest & Cutoff & Validity & Factorial study \\
\hline $\begin{array}{l}0.83 \text { in a sample of older } \\
\text { adults }^{219}\end{array}$ & & $\begin{array}{l}\geq 16=\text { moderate/severe } \\
\text { depression } \\
86,219\end{array}$ & & Four-factor structure ${ }^{219}$ \\
\hline $\begin{array}{l}0.78-0.92 \text { in a clinical } \\
\text { sample }{ }^{70,216,222,227,228} \\
0.71-0.86 \text { in a nonclinical } \\
\text { sample }{ }^{210,218,224-226} \\
0.78-0.79^{70} \text { in a } \\
554 \text { elderly in the general } \\
\text { Chinese community, } 30 \\
\text { elderly from a Chinese } \\
\text { community center and } \\
31 \text { elderly Chinese } \\
\text { patients with depressive } \\
\text { symptoms }\end{array}$ & $\begin{array}{l}0.44- \\
0.83^{70,86,216}\end{array}$ & $\begin{array}{l}\geq 10=\text { moderate } / \text { severe } \\
\text { depression } \\
\text { Sensitivity }=97 \% \\
\text { Specificity }=84 \%^{216}\end{array}$ & $\begin{array}{l}\text { Convergent } \\
\text { PS } r=0.36, \\
\text { SS } r=0.43 \text {, } \\
\text { PANAS-PA } r=0.63^{86} \\
\text { Discriminant } \\
\text { LSS } r=-0.44, \\
\text { LSNS } r=-0.30, \\
\text { ADL } r=0.4 I^{70}\end{array}$ & $\begin{array}{l}\text { Two-factor structure }{ }^{70,86} \\
\text { Unidimensional factor } \\
\text { structure }^{218}\end{array}$ \\
\hline $0.84^{217}$ & & & $\begin{array}{l}\text { Discriminant } \\
\text { ESS-SWB-SL } r=-0.52 \text {; ESS-SWB-H } \\
r=0.56 \text {, ESS-ST } r=-0.28 \text {, LOT-O } \\
r=-0.46 \text {; Subjective health } r=-0.52 \text {, } \\
\text { BPNS } r=-0.33 \text {, RSE } r=-0.45 \text {, Social } \\
\text { relationship } r=-0.21 \text {, OASIS } r=0.59^{217}\end{array}$ & $\begin{array}{l}\text { Unidimensional factor } \\
\text { structure }^{217,243,258}\end{array}$ \\
\hline
\end{tabular}

MADRS, Montgomery-Åsberg Depression Rating Scale; CATI, Coolidge Axis II Inventory-Anxiety Subscale; BHS, Beck Hopelessness Scale; BSI, Beck Scale for Suicide Ideation; PSS, Perceived Stress Scale; SCL-90-R, Symptoms Check List-90-Revised; SPWB, Short Psychological Well-Being Scale; MASQ, Mood Anxiety Symptom Questionnaire; MASQ-AD, Anhedonic depression subscale of the MASQ; PSWQ, Penn State Worry Questionnaire; STICSA-T, Trait Subscale of the State-Trait for Cognitive and Somatic Anxiety; TICSA-S, Trait Somatic subscale of the State-Trait for Cognitive and Somatic Anxiety; TICSA-C, Trait Cognitive subscale of the State-Trait for Cognitive and Somatic Anxiety; STAI-T, State-Trait Anxiety Inventory; PS, Pain Scale; SS, Stress Scale; PANAS-PA, Positive and Negative Affect Schedule - positive affect; LSS, Life Satisfaction Scale; LSNS, Lubben Social Network Scale; ADL, Activities of Daily Living; ESS-SWB-SL, Subjective Well-Being subscale of the European Social Survey - satisfaction of live; ESSSWB-H, Subjective Well-Being subscale of the European Social Survey - happiness; LOT-O, Life Orientation Test - optimist; BPNS, Basic Psychological Needs Scale; RSE, Rosenberg Self-Esteem Scale; OASIS, Overall Anxiety Severity and Impairment Scale.

symptomatology in ambulatory cancer patients. ${ }^{95}$ According to Blumenthal, the continuous use of this instrument has led to its greater validity. ${ }^{116}$ The clinical utility of the SDS was evaluated "high" by Nezu et al. ${ }^{1}$ The SDS is easily and quickly administered and scored, and can readily serve as an initial screening for depression. The SDS is also suited for ongoing assessment, as repeated administrations are unlikely to be taxing to clients or clinicians. The research applicability of the SDS was also judged as "high," as well. ${ }^{1}$ The SDS has been used in numerous research studies as a brief measure of depression. Moreover, due to its brevity, it can be easily added to an assessment. Overall, based on its psychometric functioning, the SDS is probably a good but not the best choice for a depression assessment instrument for older adults at this time. Further research on its psychometric properties and norms may yield a more positive impression of this instrument in the future. ${ }^{73}$

\section{The GDS}

\section{General characteristics}

The GDS is a self-report scale specifically designed to measure depression among older adults population. ${ }^{79-81}$ It contains 30 items that may be administered orally or in written format. Each item is scored $0-1$ and is rated on dichotomous (yes/no) format. For its development 100 questions, concerning the main themes of depression were selected and administered to a mixed sample that included 
subjects suffering from depression and subjects with no history of mental illness, aged over 55 years. On the 100 items only the 30 items with higher and more significant correlations with the total score were selected. Items that assessed somatic symptoms were excluded because of their low correlation with the total score. ${ }^{79}$ Of these 30 questions, 20 indicated the presence of depression when answered positively, and 10 when answered negatively. The total score ranges from 0 (not depressed) to 30 (maximum severity of depression), with a cutoff identified at 11 for the presence of clinically relevant depressive symptoms. ${ }^{79}$ Specifically, suggested score ranges for mild, and moderate to severe depression are 11-16, and 17-30, respectively, with levels of sensitivity and specificity varying according to some extent by the sample population characteristics. ${ }^{117-120}$ Lower accuracy was found in healthy, highly educated community-dwelling older adults. ${ }^{118}$ Although the time to complete the GDS varies from 10 to 15 minutes, it takes at least 30 minutes or longer in patients who are either hearing or cognitively impaired. ${ }^{59}$ Although an specific time reference is not included in the instructions, each question is worded in the present tense to imply recent experience of depressive symptoms.

\section{Reliability}

Reliability evidence was established by the test developers in a mixed sample, subjects suffering from depression and subjects with no history of mental illness, aged over 55 years old. ${ }^{79}$ Cronbach's $\alpha$ of 0.94 , split-half reliability coefficient of 0.94 , and test-retest reliability of $0.85(P<0.001)$ were found in this normative sample. Another study examined the reliability of the GDS among 193 younger adults (age 17-55 years) because younger samples sometimes serve as control groups in studies of geriatric depression. Results yielded an alpha coefficient of 0.82 , a median correlation with the total score of 0.38 , a mean interitem correlation of 0.15 , and a split-half reliability of $0.80 .{ }^{121}$ Further evidence for reliability has been found in older adults patients with stroke $(\alpha=0.90),{ }^{88}$ for clinical and nonclinical subjects $(\alpha=0.99$; test-retest reliability $=0.94$, and split-half reliability coefficient $=0.84),{ }^{122}$ for older adults in the Veterans Administration hospital $(\alpha=0.92),{ }^{123}$ for older adults clinical sample who met DSM-IV criteria for Generalized Anxiety Disorder (GAD) $(\alpha=0.73),{ }^{124}$ for older adults nonclinical samples $(\alpha=0.91),{ }^{93,125}$ for healthy nursing home residents $(\alpha=0.88),{ }^{126}$ for older adults diagnosed with $\operatorname{GAD}(\alpha=0.73),{ }^{124}$ and hospitalized older adults $(\alpha=0.92) .{ }^{123}$ Smarr and Keefer reported Cronbach's $\alpha$ ranging from $0.69-0.99$, based on the results of Lopez et al. ${ }^{119,127}$ Particularly, in a sample $(\mathrm{N}=417)$ of older adults medical outpatients, they found Cronbach's $\alpha$ to be $0.89,0.87,0.89$ for outpatients with Mini Mental State Examination (MMSE) scores $>17, \leq 17$, and total sample, respectively. ${ }^{128}$

\section{Convergent and discriminant validity}

Test developers showed the higher ability of the GDS ( $t=8.51 ; P=0.001$ ), to differentiate between nondepressed and depressed older adults individuals, as compared to the $\operatorname{SDS}(t=5.38 ; P=0.120)$, and the Hamilton Rating Scale for Depression (HRS-D) $(t=6.77 ; P=0.58) .{ }^{80,104}$ A later comparison of the ability to differentiate nondepressed, mildly depressed, and severely depressed individuals (diagnosed according to the Research Diagnostic Criteria) showed the GDS to be comparable to the HRS-D ( $F$-scores of 99.48 and 110.63 , respectively), ${ }^{129}$ and superior to the SDS (44.75).${ }^{79} \mathrm{In}$ the normative sample, the correlations between the GDS and the SDS ( $r=0.84 ; P<0.001)$, and with the HRS-D; $(r=0.83$; $P<0.001)$ were high. ${ }^{79}$ High correlations were also found between the GDS and other scales by Snyder et al. ${ }^{124}$ For example, GDS and SDS $0.88(P<0.001)$; GDS and CES-D, $0.82(P<0.001)$; GDS and HRS, $0.77(P<0.001)$; GDS and CPRS-D, $0.86(P<0.001)$. The correlation between GDS and the BDI has been found also high $(r=0.78 ; P<0.0001)$ in a clinical sample of older adults. ${ }^{124}$ Regarding its correlation with anxiety and the quality of life, correlations between the GDS and the Spielberger State-Trait Anxiety InventoryTrait Scale (STAI-Trait) were high $(r=0.47, P<0.01),{ }^{130}$ and with the Quality of life inventory (QOLI) in a clinical sample affected by GAD $(r=0.49, P<0.01) .{ }^{124,131,132}$ Evidence supporting the use of the GDS with cognitively impaired individuals, instead, were mixed, with Feher et al confirming it as a valid measure of mild-to-moderate depression in Alzheimer's patients with mild-to-moderate dementia. ${ }^{133}$ Indeed, some dementia patients disavow memory loss and tend to deny depressive symptoms on the GDS. Consequently, the use of the GDS in patients with severe dementia is not reccomended. ${ }^{82,134,135}$ The correlation of the GDS with the CS was instead relatively high $(r=0.77$, $P<0.01)$ in patients with mild dementia diagnosed with score of 22 or less on the MMSE, ${ }^{136}$ but weaker $(r=0.37$; $P<0.17)$ with increased cognitive impairment. ${ }^{88}$ On the other hand, the GDS has been found to have: 1) better sensitivity and specificity than the HRS-D and the SDS in older adult psychiatric patients, discriminating better between 
the depressed and not depressed; ${ }^{137} 2$ ) moderate sensitivity $(82 \%)$ and specificity $(86 \%)$ with dementia patients in a long-term care facility using the diagnosis of a psychiatrist as the criterion measure, ${ }^{138} 3$ ) moderate sensitivity $(82.6 \%)$ and specificity $(81.3 \%)$ in an inpatient, mostly cognitively impaired, geriatric sample. ${ }^{139}$ Moreover, Allen-Burge et al reported gender effects on the GDS, with poorer detection of depression in males. ${ }^{140}$

\section{Factorial structure}

Different factorial structure models of the GDS were proposed in different samples. In a nonclinical sample of older adults, while Sheikh et al found a five-factor solution, which accounted for $42 \%$ of the total variance ("Sad mood," "Lack of energy," "Positive mood," "Agitation," and "Social withdrawal"), ${ }^{141}$ Parmelee et al found a six-factor solution, accounting for $52.3 \%$ of the total variance ("General dysphoria," "Worry," "Withdrawal/apathy," "Vigor," "Decreased concentration," and "Anxiety"). ${ }^{125}$ Salamero and Marcos in their factorial analysis of a nonclinical older adults sample aged 60-95 years had found three factors that explained only $36 \%$ of the total variance. The results found, however, are not satisfactory. ${ }^{142}$ Adams et al found a five-factor solution in a nonclinical sample of 294 older adults aged 60-98 years that accounted for $50.4 \%$ of the total variance ("Dysphoric Mood," "Hopelessness," "Withdrawal-Apathy-Vigor," "Worry" and "Cognitive"). ${ }^{143}$ In a meta-analysis conducted by Kim et al, the role of language was analyzed in 26 studies, given that the GDS was translated into several languages. ${ }^{144}$ Regarding the factorial structure, results showed how analyses of the individual language adaptation provided structures ranging from 2 to 9 factors, although the fourfactor structure resulted to be the best fitting. Three factors, called "Dysphoria," "Social withdrawal-apathy-cognitive impairment," and "Positive mood," commonly emerged, with "Positive mood" factor being the most similar across different languages.

\section{Clinical utility}

The GDS appears to be a useful screening instrument for depression in geriatric populations. Its clinical utility was evaluated as "high" by Nezu et al because the guidelines for interpretation are useful for gaging the severity of depression in older adults population. ${ }^{1}$ Although it has been validated in a wide range of populations, the use of the GDS in different contexts is highly questioned. Lesher suggested that GDS may be useful for assessing Major Depression in older adults in a nursing home context. ${ }^{122}$ According to Montorio and Izal, ${ }^{145}$ the GDS has an excellent diagnostic accuracy in the community-dwelling older adults, but not in institutionalized older adults. Indeed, depressed individuals were more likely to fail to complete at least one item correctly. ${ }^{146}$ In addition, based on the results obtained by Gallagher et al, ${ }^{147}$ Yesavage et al who claimed that the GDS could also be used for depressed older adults with physical disabilities in addition to depressed but physically healthy older adults. ${ }^{79}$ Given the mixed findings deriving from studies on the use of the GDS with cognitively impaired populations, Yesavage and Sheikh recommended the use of their test in mild or moderate dementia. ${ }^{82}$ Wancata et al warned about using it with marked cognitive impairment. ${ }^{135}$ As a practical measure, Stiles and McGarrahan suggested to initially screen the older individuals suspected of cognitive impairment using the MMSE. ${ }^{120}$ With scores less than 15 , the GDS score is suspect and can be disregarded as unreliable. Instead, with scores below 24, a GDS cutoff of 14 is suggested.

\section{Geriatric depression Scale-Short form (GDS-S)}

\section{General characteristics}

The Geriatric Depression Scale-15 (GDS-15 or GDS-SF) is a 15 -item version of the $\operatorname{GDS},{ }^{82}$ developed to overcome fatigue and difficulty in maintaining the attention during the compilation of the test often found in older adults. Indeed, the time to complete the test varies from 2 to 5 minutes. ${ }^{119}$ Of the 30 items of the GDS, the 15 items with greatest correlations with depressive symptoms were selected. The dichotomous response format ("yes/no" format) is unchanged. Of the 15 items, 10 indicated the presence of depression with affirmative answer, the remaining five indicated depression with negative answer. Initially, the GDS-15 was validated on a sample of 35 older adults (18 from the community, 17 from a variety of treatment settings for complaints of depression). In this sample, both the forms of the GDS differentiated between depressed and nondepressed patients, with a high correlation $(r=0.84$, $P<0.001){ }^{82}$ Similarly, Lesher and Berryhill found a strong correlation between scores on the long and short forms of the GDS in a clinical sample of older adults $(r=0.89, P<0.01)$ and similar sensitivity and specificity with heterogeneous diagnostic groups. ${ }^{148,149}$ Baker and Millaer found support for its sensitivity and specificity when used with medically ill skilled nursing home residents, ${ }^{150}$ whereas Burke, Roccaforte 
and Wengel found less support when used with cognitively impaired individuals. ${ }^{151}$ In a recent systematic review by Pocklington et al, ${ }^{152}$ the recommended cutoff scores ranged from 4 to 6 in various older adult populations.

\section{Reliability}

In a clinical sample of patients with diagnosis of depressive disorder according to the criteria of the International Statistical Classification of Diseases, Injuries and Causes of Death (ICD-10), ${ }^{153}$ the Cronbach's $\alpha$ was $0.81 .{ }^{10}$ In nonclinical older adults samples, the alpha coefficients ranged between 0.75 and $0.76 .{ }^{154,155} \mathrm{In}$ a recent study on a nonclinical sample of 204 Iranian older adults, the Cronbach's $\alpha$ was higher ( $\alpha=0.90$ ), the split-half coefficient was 0.89 , and test-retest reliability after 2 weeks was $0.58(P<0.001) .{ }^{156}$ Furthermore, correlations $(r=0.84-0.85, P<0.01)$ at $1-2$ weeks retest suggested that the GDS scores reflected stable individual differences. ${ }^{119}$

\section{Convergent and divergent validity}

Among 72 older adults, both the long and short forms of the GDS were administered to three diagnostic groups were identified: depressed patients, patients with dementia, and patients with thought disorders. The Pearson correlation between the two forms was high for the total sample $(r=0.89, P<0.001)$, depressed patients $(r=0.90 ; P<0.001)$, patients with thought disorders $(r=0.91 ; P<0.001)$, and lower for the patients with dementia $(r=0.60 ; P<0.001) .{ }^{148}$ In a clinical sample of older adults ranging in age from 65 to 89 years, the correlation between the GDS-15 and Montgomery Åsberg Depression Rating Scale (MADRS) was high $(r=0.78, P<0.0001) .{ }^{157,158}$ Friedman et al investigated the construct validity of the GDS-15 in a nonclinical sample of older adults sample (ranging in age from 65 to 100 years) by examining correlations between its total score and the presence of major depression as indicated by the Mini-International Neuropsychiatric Interview Major Depressive Episode (MINI-MDE). ${ }^{155,159}$ Receiver operating curve analyses supported the criterion validity of the GDS-15 in successfully differentiating between depressed from nondepressed participants ( $\mathrm{AUC}=0.858, \mathrm{SE}=0.018$, $95 \%, \mathrm{CI}=0.823-0.892) .{ }^{155}$

\section{Factorial structure}

Factor-analytic studies of the GDS-15 most frequently identified a two-factor solution was most frequently identified. However, a stable factor solution was not consistently found across studies and samples, as the nature of factors extracted in various studies changed. Friedman et al examined the factor structure of the GDS-15 in a nonclinical sample of 960 adults aged 65 and older. ${ }^{155}$ They found five factors, that accounted for $54 \%$ of total variance, but retained only two factors, the most clinically and theoretically reasonable (explaining 33\% of the variance), labeled "Depression" and "Positive affects." Similarly, in a clinical sample of older people aged 59-85 years, Malakouti et al found two factors, ${ }^{156}$ namely, "Depression" (which included 11 items and explained $49.1 \%$ of the variance) and "Psychosocial activities" (which included three items, and explained $9 \%$ of the variance). Cronbach's $\alpha$ s for the two factors were 0.92 and 0.52 , respectively, and their intercorrelation was 0.50 $(P<0.001)$. In the sample of nondemented, demented, and depressed older adults, a two-factor model, including "Life satisfaction" and "General Depressive Affect" factors, was found stable across the nondemented and demented samples, but only one factor was evident in the depressed older adults, suggesting that poor life satisfaction impacts score on the GDS-15. ${ }^{160}$

\section{Clinical utility}

The most desirable features of the GDS-15 are its ease of administration and economy of time, important characteristics for a depression scale for the older adults. ${ }^{82}$ Pocklington et al provided an updated report of the widespread use of the GDS-15 in both practice and research across different linguistic and clinical settings. ${ }^{152}$ The GDS- 15 offers an added value in the primary care detection of late-life depression when compared to the original longer form, as well as other tools (eg, the BDI). ${ }^{135,155,161,162}$ Particularly, Mitchell et al's recent meta-analysis reported that its higher mean sensitivity ( $81 \%$ vs $77 \%$ ) and specificity ( $78 \%$ vs $65 \%$ ) compared to the GDS long form. ${ }^{161,162}$ In addition, the GDS-15 showed significantly higher efficiency ( $78 \%$ vs $71 \%$ ), computed as the proportion of all cases who were either true positives or true negatives, ${ }^{163}$ and utility ( 0.75 vs 0.60$)$, as defined by the clinical Utility Index. ${ }^{164}$ These findings were confirmed by a recent meta-analysis. ${ }^{152}$ However, while some recommended the use of the GDS-15 for screening major depressive disorder in older adults, ${ }^{156}$ other authors affirm that the longer form is more reliable and valid in care home settings, ${ }^{162}$ and in nursing homes. ${ }^{135}$

\section{Beck depression inventory-II General characteristics}

The BDI-II is one of the best-known and most widely used self-report questionnaire for measuring the severity of depression in diagnosed patients and for detecting possible 
depression in normal populations of adults and adolescents aged 13 years and older. It is currently available in more than 10 languages. ${ }^{165-171}$ Compared to its predecessors, the Beck Depression Inventory-I (BDI-I; Beck et al) and the Beck Depression Inventory-IA (BDI-IA; Beck \& Steer), ${ }^{105,172}$ the BDI-II was designed to align more closely with the diagnostic criteria for major depressive disorder (MDD) as operationalized in the fourth edition of the DSM, ${ }^{173}$ and to include atypical and severe depressive symptoms.

The BDI-II is composed of 21 items, each representing a symptom characteristic of depression, such as guilt, low mood, loss of interest, suicidal thoughts, and worthlessness. For each symptom, patients rate how they have felt in the last two weeks (in line with the diagnostic criteria for MDD of the DSM-IV), ${ }^{173}$ on a Guttman scaling designed to assess the depression levels. This is a graded series of four alternative statements, representing ascending levels of severity, from the absence of a given symptom (eg, "I do not feel disappointed in myself") to a maximum level of severity (eg, "I hate myself"). The items are scored from 0 to 3 , with the sum of the scores representing the BDI-II total score, which can range from 0 to 63 . Scores from 0 to 13 indicate minimal depression, scores from 14 to 19 mild depression, scores from 20 to 28 moderate depression, and scores from 29 to 63 severe depression. ${ }^{83}$ However, contrary to these score ranges suggested by the authors' manual for the BDI-II, other authors established different cutoff scores in specific populations. For example, using a cutoff of 16, the BDI-II seems to be an adequate screening tool for depressive disorders in advanced cancer patients with an average age of 60 years. ${ }^{174}$ In any case, this scale was developed as a quantitative measure of depression and was not originally designed to yield a discrete or categorical diagnosis of depression, thus such scores should not be used as the sole source of information for diagnostic purposes. ${ }^{83}$ Rather, it was developed to assess the depression as one single dimension of psychopathology that cuts across a wide variety of diagnostic categories. It can usually be completed in 5-10 minutes.

\section{Reliability}

The test-retest reliability coefficient estimated by the test developers on 26 outpatients from a normative sample including older adults, was equal to 0.93 , considering an average time interval of 7 days between application and the reapplication of the scale. ${ }^{83}$ With regard to its internal consistency, coefficient alphas estimates were found to be 0.92 and 0.93 for a psychiatric outpatient sample $(\mathrm{N}=500)$, and 0.93 for a group of college students $(\mathrm{N}=120)$ in the manual. ${ }^{83}$ Other studies documented its adequate internal consistency with Cronbach's $\alpha$ that ranged between 0.76 and 0.91 in American older adults, ${ }^{175}$ community-dwelling older adults, ${ }^{176,177}$ Puerto Rican older adults, ${ }^{178}$ older cardiac patients, ${ }^{179}$ and women residing in retirement communities. ${ }^{180}$ Among medical samples of older adults with a mean age of 62 years, the internal consistency ranged from 0.89 to $0.92 .^{181-183}$ Good reliability and validity were obtained by administering the BDI-II via telephone to the older adults diagnosed with generalized anxiety disorders. ${ }^{184}$

\section{Convergent and discriminant validity}

The construct validity of the BDI-II was mainly supported by its significant relationships with its predecessor and with other measures of depression. The BDI-II manual (Beck et al) reported correlations of $0.93(P<0.05)$ and $0.84(P<0.05)$ with its predecessor in two samples of 191 subjects, including older adults, and 84 outpatients, as well as a correlation of 0.71 $(P<0.05)$ with the Revised Hamilton Psychiatric Rating Scale for Depression (HRS-D-R). ${ }^{83,185}$ Furthermore, test developers reported correlations of $0.68(P<0.05)$ and $0.37(P<0.05)$ with the Beck Hopelessness Scale (BHS) and the Beck Scale for Suicide Ideation (BSI), both constructs generally viewed to be conceptually related to depression. ${ }^{186,187,271}$

Segal et al found a solid evidence for convergent and discriminant validity of the BDI-II in a sample of communitydwelling older and younger adults. ${ }^{177}$ The BDI-II was significantly and positively correlated $(r=0.69, P<0.001)$ with the CES-D, and $(r=0.66, P<0.001)$ with the Coolidge Axis II Inventory (CATI), ${ }^{188}$ as well as with the CATI Anxiety subscale $(r=0.60, P<0.001)$ the CATI Anxiety subscale $(r=0.60$, $P<0.001)$, and with OAS $(r=0.45, P<0.01) .{ }^{272}$ Regarding psychological well-being, the BDI-II was significantly and negatively correlated $(r=-0.60, P<0.001)$ with the Short Psychological Well-Being Scale (SPWB) total score and each of the six SPWB subscales ( $r$ s ranging from -0.31 to $-0.64, P<0.001) .{ }^{189}$ Regarding the stress, the BDI-II was significantly and positively correlated $(r=0.64, P<0.001)$ with the Perceived Stress Scale (PSS) score. ${ }^{190}$ Regarding health status, the BDI-II was significantly and negatively correlated ( $r=-0.27, P<0.001$ ) with subjective health. A significant positive correlation $(r=0.71, P<0.001)$ was also found between the BDI-II score and the total score of GDS in community-dwelling older women, ranging in age from 65 to 91 , with mean age of $77 .{ }^{180}$ One of the criticism of the BDI-II, that probably generalizes to all depression instruments is that this instrument does not discriminate adequately between depression and anxiety. ${ }^{72}$ However, it was also more strongly 
associated with the Depression subscale of the Symptoms Check List-90-Revised $(r=0.89, P<0.05)$ than the Anxiety subscale of the same instrument $(r=0.71, P<0.05){ }^{191,192}$

\section{Factorial structure}

According to the BDI-II manual, ${ }^{83}$ two two-factor models emerged consistently by iterated principal exploratory factor analyses. The first model, that emerged in the psychiatric outpatient sample, was termed somatic-affective and cognitive (SA-C), and the second model, that emerged in the student sample, was labeled as cognitive-affective and somatic dimensions (CA-S). Some items were consistent indicators of the cognitive dimension and other items consistently define the somatic dimension. The remaining items variably load on one factor or the other to produce either a CA factor or an SA factor. A study by Steer et al confirmed the noncognitive (somatic-affective) and cognitive dimensions of the BDI-II as identified by Beck et al in depressed geriatric inpatients. ${ }^{83,181}$ However, a confirmatory factor analysis with multiple-group analysis in a sample of community-dwelling older adults showed that the Steer et al's model did not fit the data well, ${ }^{181}$ probably due to methodological factors such as the different nature of the samples (depressed patients vs nonpsychiatric community-dwelling individuals) and the different types of extraction techniques (iterated Maximum-Likelihood Factor Analysis vs CFA with multiple-group analysis). ${ }^{177}$ According to a study with Puerto Rican older adults, the items that make up the BDI-II could be grouped into four factors: negative attitudes, cognitive-behavioral, biological and somatic factors. ${ }^{178}$ However, a stable factor solution was not consistently found across studies and samples, and the number of factors extracted in various studies ranged anywhere from 1 to $7 .{ }^{193}$

\section{Clinical utility}

The clinical utility of the BDI-II was classified as "high" by Nezu and colleagues, ${ }^{1}$ because of its clinical sensitivity and specific consistence with DSM-IV criteria. Among the positive features of the BDI-II are the fact that it likely captures as many depressive symptoms as possible and has been frequently considered the most widely used screening instrument in large-scale population-based studies among cognitively normal older adults persons, ${ }^{194}$ and to assess depressive symptomatology in older nonclinical samples. ${ }^{178,180}$ Indeed, it is brief, easily scored, and easily administered. ${ }^{83}$ Moreover, BDI-II has been proven to be a helpful instrument for clinicians who work with depressed geriatric inpatients. ${ }^{181}$ On the negative side, the self-report nature of the BDI may affect its results due to response sets, such as social desirability or respondent educational attainment, or the gender effect. ${ }^{195-197}$ For example, older women seem to be more hesitant to complete the BDI-II than other measures of depression. ${ }^{180}$ In addition, individuals with cognitive impairment might have difficulty completing the BDI-II, particularly linked to the Guttman response scale. ${ }^{198}$ This difficulty is reflected by higher false positive rates in Alzheimer's patients. ${ }^{199}$ Interestingly, these differences cannot be attributable to somatic symptoms. However, the somatic content of some items may complicate interpretation of scores, as the complaints can result from depression, physical disorders, or both. ${ }^{177}$ These results reinforce the need to consider the influence of older adults' somatic complaints when assessing depression, particularly among medical patients. ${ }^{200}$

\section{Center for Epidemiological Studies Depression Scale (CES-D)}

\section{General characteristics}

The Center for Epidemiological Studies Depression Scale (CES-D) is a 20-item self-report measure designed from large-scale epidemiological studies in the general population to measure current levels of depression. ${ }^{84}$ Each item provides a statement representing a symptom characteristic of depression (for example "I had crying spells") and is rated on a four-point Likert-type scale for frequency of symptoms in the last week. Sixteen items range from 0 ("rarely or none of the time," that is less than 1 day) to 3 ("most all of the time," that is $5-7$ days), representing ascending frequency, while four items are written in the opposite direction (from 3 to 0 ), representing descending levels of frequency. The sum of the ratings of the 20 items provides a total score, ranging from 0 to 60 with the higher scores indicating higher frequency of depressive symptomatology experienced during the past week. Originally, items of the CES-D were chosen from other existing valid measures of depression to cover the areas of depressed mood, feelings of helplessness, loss of energy, and disturbances of sleep and appetite. ${ }^{201}$ Norms were based on three community samples and two psychiatric patient samples, including 4,996 nonpatient adults, and 70 adult psychiatric patients. ${ }^{84}$ The CES-D consistently demonstrates four factors: "depressed affect," "positive affect," "somatic and retarded activity," and "interpersonal relations" across multiple subgroups, including older adult samples, and with the general population, ${ }^{84,202,203}$ although some items cross factors across studies. This requirement is fundamental for instruments intended for epidemiological studies, and therefore to be generalized across subgroups. The CES-D has been translated into different languages and 
used in clinical, community-based, and older adults living in residential homes settings. ${ }^{204-210}$ Originally, a cutoff score of 16 was found as a suitable indicator to differentiate between depressed and nondepressed patients. ${ }^{84,211}$ However, high rates of false-positives with the suggested cutoff scores of 16 were reported in medical patients by Schein and Koenig. ${ }^{212}$ Consequently, they suggested a two-stage approach to the use of the CES-D in this population to improve diagnostic efficiency. First, examinees must meet the minimum cutoff total score of 16. Second, the examinee must obtain a score of at least four on the depressed affect subscale. Of note, Radloff and Teri highlighted that, while mean scores for males consistently increased with age, mean scores for females were highest in the 55-59 and 75 and older groups and lowest for the 60-75 years old. ${ }^{201}$ More recent studies designated a cutoff score of 15 in the general geriatric population to have sensitivity ranging from $57 \%$ to $100 \%$ and specificity ranging from $68 \%$ to $88 \% .^{71,213,214}$ However, no indicators have been designated to discriminate depressive subtypes or to distinguish primary from secondary depression. Thus, as Radloff and Nezu et al concluded, appropriate cutoff of the CES-D for clinical screening is yet to be validated. ${ }^{1,84}$ Indeed, as seen in cutoff scores for all the measures, investigators suggested that this may be too low for some older adult populations, producing too many false-positives, ${ }^{22,215}$ and too high for detecting depression in healthy populations. ${ }^{118}$

\section{Reliability}

In normative sample internal consistency coefficient alpha estimates were found to be 0.85 for the general population and of 0.90 for the patient sample. ${ }^{84}$ Also Himmelfarb and Murrel found $\alpha$ s of 0.85 in nonclinical sample and 0.90 in clinical samples of older adults. ${ }^{22}$ Recent studies showed good reliability both in nonclinical older adults (from $\alpha=0.81$ to $\alpha=0.93),{ }^{71,177,207,220,221}$ and clinical samples of older adults, such as older medical inpatients $(\alpha=0.86),{ }^{212}$ and older adult caregivers $(\alpha=0.88) .{ }^{203}$ Again, Zhang et al confirmed these results through omega coefficients both in Chinese ( $\omega$ values ranging from 0.72 to 0.87 ) and Dutch ( $\omega$ ranging from 0.74 to 0.82 ) samples of dwelling older adults. ${ }^{222}$ A recent study found an $\alpha$ values of 0.89 among a sample of urban community-dwelling older adults. ${ }^{223}$

Regarding the short forms, $\alpha$ estimates of the CES-D-10 were found to be ranging from 0.71 and 0.86 in a nonclinical sample of older adults aged of 65 and over, ${ }^{210,218,224-226}$ and from 0.78 to 0.92 in a clinical sample of older adults aged 55 and over. ${ }^{70,216,222,227,228}$ Test-retest reliability was reasonably good (ranging from $r=0.44$ to $r=0.83 ; P<0.01$ or less). ${ }^{70,86,216}$
The split-half coefficient was $0.65(P=0.01)$, while the testretest reliability after 2 weeks was $0.49(P=0.01) .{ }^{210}$ The CES-D- 8 showed an $\alpha$ value of 0.84 in a large sample of European older adults. ${ }^{217}$ Recently, an 11 -items version of the CES-D has been used. ${ }^{85}$ This version showed an $\alpha$ of 0.83 in a sample of older adults, ranging from 65 to 101 years, from a range of urban and rural areas. ${ }^{219}$

\section{Convergent and discriminant validity}

Strong evidence supports the construct validity of the CES-D and its short forms scores as measures of various aspects of depression. ${ }^{22,71,202}$ The CES-D-20 showed a significant correlation of $0.69(P<0.001)$ with the BDI-II in a community-dwelling older adults, ${ }^{177} r=0.50(P<0.001)$ with the depression scale of the Hospital Anxiety and Depression Scale (HADS-D) in older adults residents of long-time care, ${ }^{221,229} r=0.82(P<0.001)$ with the GDS, $r=0.74$ $(P<0.001)$ HRS, $r=0.83(P<0.001)$ with the CPRS-D, and $r=0.81(P<0.001)$ with the SDS in a clinical population of stroke patients. ${ }^{88} \mathrm{~A}$ very recent study found strong and significant correlations with the BDI-II ( $r=0.75, P<0.0001)$, with the Depressive symptoms subscale of the Mood Anxiety Symptom Questionnaire (MASQ) $(r=0.75, P<0.0001),{ }^{230}$ and with the Anhedonic depression subscale of the MASQ ( $r=0.72, P<0.0001) .{ }^{231}$ Regarding discriminant validity, the CES-D showed low correlations with anxiety measures like the Penn State Worry Questionnaire (PSWQ) $(r=0.36$, $P<0.05),{ }^{232-234}$ the State-Trait Inventory for Cognitive and Somatic Anxiety (STICSA) ( $r=0.59)$ with Trait subscale, $r=0.47$, Somatic subscale, $r=0.61$ with the Cognitive subscale $(P<0.0001)$ and, ${ }^{235}$ with the Trait subscale of the State-Trait Anxiety Inventory (STAI) $(r=0.70, P<0.0001) .{ }^{130,231}$ Górkiewicz and Chmiel found no significant correlation with the Barthal Index. ${ }^{221,236}$ Regarding the short forms of the CES-D, Andresen et al originally showed significant $r$ value equal to $0.36(P<0.005)$ between the CES-D-10 and the Pain Scale (PS), ${ }^{86,237} r=0.43$ with the Stress Scale (TSS), ${ }^{238}$ and $r=-0.63$ with the Positive Affect Scale (PANAS-PA). ${ }^{239}$ Consistent with research, ${ }^{70}$ demonstrating the inverse relationship between depression and life satisfaction $(r=-0.44, P<0.01)$ measured with the Life Satisfaction Scale (LSS), ${ }^{240}$ quality of social network ( $r=-0.30, P<0.01)$ measured with the Lubben Social Network Scale (LSNS), ${ }^{241}$ and daily functioning ( $r=0.41, P<0.01$ ) measured with Activities of Daily Living (ADL) ${ }^{242}$ Differently, studies investigating the validity of the CES-D-8 are scarce, to date. ${ }^{243}$ The discriminant validity of the CES-D-8 was supported by its negative correlations with nondepression variables such as life satisfaction $(r=-0.52$, 
$P<0.01)$ and happiness $(r=0.56, P<0.1)$ measured by the two single-item of the Subjective Well-Being subscale of the European Social Survey (EES), ${ }^{244}$ social trust assessed by three item of the Social Trust Subscale of the EES ( $r=-0.28$; $P<0.01$ ), optimism measured by the Optimist scale of Life Orientation Test (LOT), ${ }^{245}$ ( $\left.r=-0.46, P<0.01\right)$; subjective health $(r=-0.52, P<0.01)$, autonomy, measured by a singleitem of the Basic Psychological Needs Scale $(r=-0.33$, $P<0.01)$, ${ }^{246}$ self-esteem, assessed by the Rosenberg SelfEsteem Scale (RSE) $(r=-0.45, P<0.01),{ }^{247}$ social relationship $(r=-0.21, P<0.01)$ and anxiety measured by an adopted single-item of the Norman et al Overall Anxiety Severity and Impairment Scale (OASIS) $(r=0.59, P<0.01){ }^{217,248}$

\section{Factor structure}

Both exploratory and confirmatory factor analyses have suggested the different structure of the scale. With regard to the CES-D-20, Zhang et al showed that, in two samples of Chinese and Dutch nonclinical older adults aged 55 and over, Radloff's four-factor model resulted to significantly fit better compared to a single-factor, three-factor, and second-order model. ${ }^{84,222}$ Hence, a model of four dimensions of the CES-D seems to be the most informative in assessing depressive symptoms in both the Chinese and Dutch older adults populations. Regarding the CED-D-11, in a home healthcare older population aged 65 years and over, Gellis reported the latent constructs of Depressed Affect, Positive Affect, Somatization, and Interpersonal Relations, as hypothesized. ${ }^{219}$ Malakouti et al found a twofactor structure. ${ }^{210}$ These same results have been found by Andresen et al for the CES-D-10. ${ }^{86}$

\section{Clinical use}

Nezu et al evaluated the clinical utility of the CES-D as "limited." Although the instrument has good sensitivity and specificity, it is intended for research purposes only. ${ }^{1}$ Indeed, its research applicability was judged as "high" because it has been used to measure change in depressive symptomatology over time and as a screening tool for inclusion in treatment studies. Overall, the strengths of the CES-D include the availability of norms based on a large representative sample, its factor invariance across age groups, its demonstrated reliability and sensitivity in older adults, its widespread use in epidemiological studies. ${ }^{22}$ Its disadvantages include its response format, which may be difficult and somewhat less reliable among individuals with cognitive impairments, ${ }^{85}$ its differential responding patterns depending on ethnic groups, ${ }^{249}$ its low specificity at a cutoff of $16,{ }^{250-252}$ using a diagnosis of major depression as a criterion, suggested that should be better suited as a screening than diagnostic tool.

The length of the form and its of administration (it can be completed in less than 10 minutes), and the emotional stress related to questions have forced the researchers to address their efforts to develop shortened versions of the scale. ${ }^{85-87,216,253-255}$ Specifically, the CES-D-11, ${ }^{85}$ the CES-D$10,{ }^{86}$ and the CES-D-8, ${ }^{87}$ are composed of 11,10 , and 8 items. These versions are often preferred to the 20 -item original form. ${ }^{217,218}$ For example, a comparison between the CES-D-10 and the CES-D long form was quite favorable, resulting in only one misclassification using the CES-D-10. Irwin \& Owen found excellent sensitivity for major depression in older adults of the CES-D-10. ${ }^{216}$ A cutoff score of 10 or more has been used for CES-D-10 and of 16 for CES-D-11. ${ }^{86,219}$ No sensitivity has been still found for the CES-D-8. ${ }^{218}$

Again, the CES-D-11 possesses good psychometric properties when used with older adults' home care, given that in home health care, the challenge of screening lies in discriminating depression from the medical condition in older adults. Overall, in the context of routine mental health screening, the short forms of the CES-D potentially positively identify older persons experiencing depressive symptoms and may contribute to immediate individualized treatment planning. In fact, the shortened version of the CES-D does not appear to compromise the psychometric properties of the instrument and patients reported ease of use. Nonetheless, several methodological issues have to be considered. The revised 11-item CES-D has not been validated in older adult home care populations and did not use a DSM-based measure of depression due to the nature of the home care environment and time constraints on the home care provider. The psychometric results for the 11-item version CES-D look promising, and are comparable to the original scale. ${ }^{219}$ Further validation is needed to offer a briefer version of a long measure that has proven to be taxing and difficult for older persons. Such investigation would assist home care clinicians in timely evaluation of their older client's mental health status. Regarding CES-D-10, literature has demonstrated that the CES-D-10 is applicable not only to normal older adults in the community, but also to geriatric patients in the clinical setting, with comparable utility. ${ }^{70}$

\section{Discussion}

According to recent reviews and surveys, rates of major depression increase in adults over 80 years of age. This is probably due to the dramatic increase in the age group known as the "oldest old," those over age 85.,4 Moreover, 
since suicide is the major life-threatening complication of depression and the most common clinical emergency encountered in mental health practice, ${ }^{259,260}$ early detection and treatment of depression in late-life not only improves functional status and quality of life, but also contributes to prevents premature death.

Most importantly, since discriminating assessment tools and finding evaluative information on their psychometric properties vex researchers and clinicians alike and are likely to contribute to schism between research and practice, ${ }^{1,261}$ here we aimed to provide a review of the current literature on the assessment of late-life depression via self-report measures.

This is of information when deciding whether the psychometric properties of an instruments are sufficiently strong to warrant their use in either a clinical or research setting. Given that accurate and early detection and diagnosis of depression disorders in later life is crucial to initiating appropriate (pharmacologic or/and psychotherapic) treatment and can also be performed by nonpsychiatric physicians, ${ }^{16,69,177}$ rapid and sound methods of identifying preliminary indicators of depression are crucial.

Firstly, it should be emphasized that the detection and assessment of late-life depression has been overlooked, misunderstood, or even misattributed, since symptoms are often confused with other medical problems such as loss of appetite, sleep disturbances, loss of energy, involvement, and pleasure, as well as with cognitive decline. ${ }^{262}$ Late-life depression has been misinterpreted as senescence, an irreversible decline in mental and physical capabilities. Thus, a treatable disorder-like depression might be mislabeled as dementia or other chronic medical illness, or ignored altogether as less important than medical difficulties, or misdiagnosed as a largely untreatable problem. ${ }^{263}$

A critical overview of key assessment issues in the latelife assessment should include the most common complications reported below.

1. Most existing depression rating scales currently used for older adults have been developed and validated in younger populations and their applicability with older adults has not yet fully been demonstrated. This aspect is decisive in light of the qualitative age-related differences in the clusters of symptoms reported in the Introduction. At present, no current assessment self-report tools discriminate between subtypes of geriatric depression..$^{55}$ The GDS is unique in that it was specifically developed for use in geriatric patients, and it contains fewer somatic items. ${ }^{59}$ Both GSD and GDS short include questions within the past week and responses require only a "yes" or "no," making comprehension easier compared with the instruments that present four-choice answers.

2. Most extant depression self-report scales currently used for older adults (eg, BDI-II, CES-D, SDS) ignore the consider level of cognitive impairment along with visual deficits of the older patients. The validity of certain depression rating scales is significantly decreased in patients with a MMSE score equal or less to $15 .{ }^{128,264}$

3. None of the self-report depression scales currently used for older adults have items assessing differential signs of dementia. To avoid the confusion between dementia and depression in the older adults, it is crucial to be able to differentiate pseudodementia and depression. This distinction can be very difficult, but there are some key differences may be noticed. For instance, in depression 1) cognitive symptoms typically have a sudden onset, 2) symptoms such as inflated sense of guilt and self-reproach are usually also apparent, 3) recent memory is affected more than remote memory, and 4) cognitive difficulties frequently show a pattern of diurnal variation. These features are not assessed by any of the self-report measures presented here. Thus, a combination of assessment approaches (structured diagnostic interviews and selfreport measures of symptomatology) is the most useful, both diagnostically and in terms of case conceptualization and treatment planning. ${ }^{265}$

4. Most self-report depression scales currently used for older adults, eg, the BDI-II, contain items tapping somatic symptoms. When the overlap of depressive symptoms and physical conditions is high, failure to take the physical illness into account may result in an overestimation of depression in such populations. This overlap may make affect treatment efficacy very difficult. Furthermore, scores on self-report indices could be inflated, indicating a severity of depression that continues to warrant treatment. On the other hand, over attributing these symptoms to physical illness when other mood symptoms are present represents underdiagnosis. Among patients at the end of the lifespan, diagnosis also entails differentiating depression from an expectable, nonpathological reaction to terminal illness. Depression treatment among the terminally ill is important, as untreated depression can reduce the quality of a patient's limited remaining time. In attempting to differentiate between depression and medical complaints, a numbers of investigators have suggested that using questionnaires that focus less on the somatic aspects of depression and more on the cognitive 
and affective items may be the best indicators of depression and symptom change in such populations.

5. Most existing depression rating scales currently used for older adults, eg, the BDI-II, do not disentangle anxiety and depression. That is, they do not differentiate among these groups of patients. This lack of specificity prevents accurate differential diagnosis. ${ }^{265}$

6. Existing depression rating scales currently used for older adults, like the CES-D, the GDS, the GDS-SF, vary in terms of their primary content focus and their coverage of the core symptoms of depressive symptomatology. ${ }^{57,266}$ This could result in the underrecognition of depressive symptoms.

7. Most existing depression rating scales currently used for older adults, like the CES-D, contain such statements that may lead to problems of interpretation. ${ }^{116}$ For example, statements about suicidal intent, whether life is worth living, or whether one is hopeful about the future have different meanings in those at the end of their lifespan. These problems of unique interpretation can probably be dealt with adequately if an experienced interviewer administers the depression scale, and the scale is designed to elicit more open-ended responses from the patient in an atmosphere fostering good relationships. However, in designing a self-rating depression scale older adults, these issues need to be adequately addressed in the scale's initial development. Despite its ubiquity, depression has been difficult to define and often means different things to different people. ${ }^{1}$

8. Most existing depression rating scales currently used for older adults did not differentiate unipolar depressive from bipolar disorder symptoms, given the high degree of symptom overlap. The issue of under-recognized features indicative of bipolar disorder among patients with ostensibly unipolar depression is of high clinical importance but is controversial. ${ }^{267}$ According to some authors, ${ }^{268,269}$ approximately one-quarter of depressive patients recalled no manic or hypomanic episodes previously experienced, thus were misdiagnosed as the unipolar depression in primary care practices. Such potential misdiagnosis has important consequences for care because such patients are at increased risk for suicide, and, given treatment approaches for unipolar and bipolar disorder differ substantially, their condition might deteriorate or become treatment refractory, ${ }^{270}$ if bipolar symptoms are not managed appropriately. Timely recognition of bipolar disorder by primary care physicians via self-report measures could provide long-lasting benefits for the patient even because treatment approaches for unipolar and bipolar disorder differ substantially. ${ }^{267}$

\section{Conclusion}

The need for scientifically sound, but practical clinical tools is relevant for clinical assessment, intervention, and research of late-life depression. Here, several measurement issues related to assessment of depression have been examined in the Introduction.

Summing up, the use of depression self-report measures in older adults varies with their cognitive status. In cognitively intact or mildly impaired patients older than 65 years, the GDS or GDS short are currently the preferred instruments because the psychometric functioning of the BDI-II and CES-D are mixed in this population. ${ }^{262}$ In cognitively impaired patients, interviewer-administered instruments should be preferred. ${ }^{59}$

The use of depression self-report measures in older adults also varies with their clinical presentation. Depressed older adults may also present with unexplained somatic symptoms and may deny low mood or loss of pleasure. Consequently, clinical judgment may be more helpful than screening measures. ${ }^{59}$

\section{Disclosure}

The authors report no conflicts of interest in this work.

\section{References}

1. Nezu AM, Ronan GF, Meadows EA, McClure KS. Practitioner's guide to empirically based measures of depression. 2000.

2. Marcus M, Yasamy MT, van Ommeren M, Chisholm D, Saxena S. Depression: a global public health concern. 2012.

3. Blazer DG. Depression in late life: review and commentary. J Gerontol A Biol Sci Med Sci. 2003;58(3):M249-M265.

4. Steffens DC, Skoog I, Norton MC, et al. Prevalence of depression and its treatment in an elderly population: the Cache County study. Arch Gen Psychiatry. 2000;57(6):601-607.

5. Baltes MM, Wahl H-W, Schmid-Furstoss U. The daily life of elderly Germans: activity patterns, personal control, and functional health. J Gerontol. 1990;45(4):P173-P179.

6. Lachman ME. Personal Control in Later Life: Stability, Change, and Cognitive Correlates. In: Baltes MM, Baltes PB, editors. The Psychology of Control and Aging. Hillsdale, NJ: Erlbaum; 1986:207-236.

7. Sözeri-Varma G. Depression in the elderly: clinical features and risk factors. Aging dis. 2012;3(6):465.

8. Rodda J, Walker Z, Carter J. Depression in older adults. BMJ. 2011; 343:d5219.

9. Areán PA, Ayalon L. Assessment and treatment of depressed older adults in primary care. Clinic Psychol: Sci Pract. 2005;12(3):321-335.

10. Almeida OP, Almeida SA. Confiabilidade da versão brasileira da Escala de Depressão em Geriatria (GDS) versão reduzida. Arq Neuropsiquiatr. 1999;57(2B):421-426.

11. Friedman B, Conwell Y, Delavan RL. Correlates of late-life major depression: a comparison of urban and rural primary care patients. $A m$ Geriatr Psychiatry. 2007;15(1):28-41. 
12. Gilchrist G, Gunn J. Observational studies of depression in primary care: what do we know? BMC Fam Pract. 2007;8(1):28.

13. Brodaty H, Luscombe G, Parker G, et al. Early and late onset depression in old age: different aetiologies, same phenomenology. J Affect Disord. 2001;66(2-3):225-236.

14. Meeks TW, Vahia IV, Lavretsky H, Kulkarni G, Jeste DV. A tune in "a minor" can "b major": a review of epidemiology, illness course, and public health implications of subthreshold depression in older adults. J Affect Disord. 2011;129(1-3):126-142.

15. Volkert J, Schulz H, Härter M, Wlodarczyk O, Andreas S. The prevalence of mental disorders in older people in Western countries - a metaanalysis. Ageing Res Rev. 2013;12(1):339-353.

16. Grover S, Malhotra N. Depression in elderly: a review of Indian research. J Geriatr Mental Health. 2015;2(1):4.

17. Fiske A, Wetherell JL, Gatz M. Depression in older adults. Annu Rev Clin Psychol. 2009;5(1):363-389.

18. Kennedy GJ, Castro J, Chang M, Chauhan-James J, Fishman M. Psychiatric and medical comorbidity in the primary care geriatric patient - an update. Curr Psychiatry Rep. 2016;18(7):62.

19. Beekman ATF, Penninx BWJH, Deeg DJH, et al. Depression in survivors of stroke: a community-based study of prevalence, risk factors and consequences. Soc Psychiatry Psychiatr Epidemiol. 1998;33(10): 463-470.

20. Untzer J, Patrick DL, Diehr P, Simon G, Grembowski D, Katon W. Quality adjusted life years in older adults with depressive symptoms and chronic medical disorders. Int Psychogeriatr. 1999;12(1):15-33.

21. Unützer J, Katon W, Callahan CM, et al. Collaborative care management of late-life depression in the primary care setting: a randomized controlled trial. JAMA. 2002;288(22):2836-2845.

22. Himmelfarb S, Murrell SA. Reliability and validity of five mental health scales in older persons. J Gerontol. 1983;38(3):333-339.

23. Bruce ML, Leaf PJ. Psychiatric disorders and 15-month mortality in a community sample of older adults. Am J Public Health. 1989;79(6):727-730.

24. Somervell PD, Leaf PJ, Weissman MM, Blazer DG, Bruce ML. The prevalence of major depression in black and white adults in five United States communities. Am J Epidemiol. 1989;130(4):725-735.

25. Ncfh S. Advance report of final mortality statistics, 1988. Mon Vital Stat Rep. 1990;39(7):1-47.

26. de Leo D, Padoani W, Scocco P, et al. Attempted and completed suicide in older subjects: results from the WHO/EURO multicentre study of suicidal behaviour. Int J Geriatr Psychiatry. 2001;16(3):300-310.

27. Clark DC, Fawcett J. Review of empirical risk factors for evaluation of the suicidal patient. 1992.

28. Clark DC, Fawcett J. An empirically based model of suicide risk assessment for patients with affective disorder. 1992.

29. Corna LM, Cairney J, Streiner DL. Suicide ideation in older adults: relationship to mental health problems and service use. Gerontologist. 2010;50(6):785-797.

30. Cairney J, Corna LM, Streiner DL. Mental health care use in later life: results from a national survey of Canadians. The Canadian Journal of Psychiatry. 2010;55(3):157-164.

31. Conwell Y. Suicide in later life: a review and recommendations for prevention. Suicide Life-Threatening Behav. 2001;31(Suppl I):32-47.

32. Alzheimer's Association. Alzheimer's disease facts and figures. Alzheimers Dement. 2018;14(3):367-429.

33. Pláteník J, Fišar Z, Buchal R, et al. GSK3 $\beta$, CREB, and BDNF in peripheral blood of patients with Alzheimer's disease and depression. Progr Neuro-Psychopharmacol Biol Psychiatry. 2014;50:83-93.

34. Rapp MA, Dahlman K, Sano M, Grossman HT, Haroutunian V, Gorman JM. Neuropsychological differences between late-onset and recurrent geriatric major depression. Am J Psychiatry. 2005;162(4): 691-698.

35. Salzman C, Shader RI. Depression in the elderly. I. Relationship between depression, psychologic defense mechanisms and physical illness. J Am Geriatr Soc. 1978;26(6):253-260.
36. Salzman C, Shader RI. Depression in the elderly. II. Possible drug etiologies; differential diagnostic criteria. J Am Geriatr Soc. 1978;26(7):303-308.

37. Kahn RL, Zarit SH, Hilbert NM, Niederehe G. Memory complaint and impairment in the aged. Arch Gen Psychiatry. 1975;32(12):1569-1573.

38. Wells CE. Pseudodementia. Am J Psychiatry. 1979;136(7):895-900.

39. Jarvik LF. Aging and depression: some unanswered questions. J Gerontol. 1976;31(3):324-326.

40. Coleman RM, Miles LE, Guilleminault CC, Zarcone VP, Hoed J, Dement WC. Sleep-wake disorders in the elderly: a polysomnographic analysis. J Am Geriatr Soc. 1981;29(7):289-296.

41. Husain MI, Chaudhry IB, Rahman RR, et al. Minocycline as an adjunct for treatment-resistant depressive symptoms: study protocol for a pilot randomised controlled trial. Trials. 2015;16(1):410.

42. Wetherell JL, Gatz M, Pedersen NL. A longitudinal analysis of anxiety and depressive symptoms. Psychol Aging. 2001;16(2):187-195.

43. Hettema JM, Kuhn JW, Prescott CA, Kendler KS. The impact of generalized anxiety disorder and stressful life events on risk for major depressive episodes. Psychol Med. 2006;36(06):789-795.

44. Balsamo M, Cataldi F, Carlucci L, Fairfield B. Assessment of anxiety in older adults: a review of self-report measures. Clin Interv Aging. 2018;13:573-593.

45. Beekman ATF, de Beurs E, van Balkom AJLM, Deeg DJH, van Dyck R, van Tilburg W. Anxiety and depression in later life: co-occurrence and communality of risk factors. Am J Psychiatry. 2000;157(1):89-95.

46. Lenze EJ, Mulsant BH, Shear MK, et al. Comorbid anxiety disorders in depressed elderly patients. Am J Psychiatry. 2000;157(5):722-728.

47. Schoevers RA, Beekman AT, Deeg DJ, Jonker C, van Tilburg W. Comorbidity and risk-patterns of depression, generalised anxiety disorder and mixed anxiety-depression in later life: results from the AMSTEL study. Int J Geriatr Psychiatry. 2003;18(11):994-1001.

48. Kaya B. Late life and depression: diagnosis and assessment. Turkish $J$ Geriatr. 1999;2(2):76-82.

49. Eker E, Noyan A. Yaşlıda Depresyon ve Tedavisi. Klinik Psikiyatri. 2004;2:75-83

50. Jorm AF. History of depression as a risk factor for dementia: an updated review. Aust N Z J Psychiatry. 2001;35(6):776-781.

51. Gallo JJ, Anthony JC, Muthén BO. Age differences in the symptoms of depression: a latent trait analysis. J Gerontol. 1994;49(6): P251-P264.

52. Gallo JJ, Rabins PV, Lyketsos CG, Tien AY, Anthony JC. Depression without sadness: functional outcomes of nondysphoric depression in later life. J Am Geriatr Soc. 1997;45(5):570-578.

53. Newmann JP, Engel RJ, Jensen JE. Age Differences in depressive symptom experiences. J Gerontol. 1991;46(5):P224-P235.

54. Alexopoulos GS. Depression in the elderly. The Lancet. 2005; 365(9475):1961-1970.

55. Powers DV, Gallagher-Thompson D, Kraemer HC. Coping and depression in Alzheimer's caregivers: longitudinal evidence of stability. J Gerontol B Psychol Sci Soc Sci. 2002;57(3):P205-P211.

56. Gallagher D, Breckenridge J, Steinmetz J, Thompson L. The Beck depression inventory and research diagnostic criteria: congruence in an older population. J Consult Clin Psychol. 1983;51(6):945-946.

57. Balsamo M, Saggino A. Test per l'assessment della depressione nel contesto italiano: un'analisi critica. Psicoterapia Cognitiva e Comportamentale. 2007;13(2):167.

58. Association AP. Diagnostic and statistical manual of mental disorders (DSM-5 ${ }^{\circledR}$ ). Am Psychiatric Pub. 2013.

59. Sharp LK, Lipsky MS. Screening for depression across the lifespan. Am Fam Physician. 2002;66:1001-1008.

60. Annen S, Roser P, Brüne M. Nonverbal behavior during clinical interviews: similarities and dissimilarities among schizophrenia, mania, and depression. J Nerv Ment Dis. 2012;200(1):26-32.

61. Fiquer JT, Boggio PS, Gorenstein C. Talking bodies: nonverbal behavior in the assessment of depression severity. J Affect Disord. 2013; 150(3):1114-1119. 
62. Girard JM, Cohn JF, Mahoor MH, Mavadati SM, Hammal Z, Rosenwald DP. Nonverbal social withdrawal in depression: evidence from manual and automatic analyses. Image Vis Comput. 2014;32(10): 641-647.

63. Philippot P, Schaefer A, Herbette G. Consequences of specific processing of emotional information: impact of general versus specific autobiographical memory priming on emotion elicitation. Emotion. 2003;3(3):270-283.

64. Uhlmann EL, Leavitt K, Menges JI, Koopman J, Howe M, Johnson RE. Getting explicit about the implicit: a taxonomy of implicit measures and guide for their use in organizational research. Organ Res Methods. 2012;15(4):553-601.

65. Balsamo M. Personality and depression: evidence of a possible mediating role for anger trait in the relationship between cooperativeness and depression. Compr Psychiatry. 2013;54(1):46-52.

66. Balsamo M. Anger and depression: evidence of a possible mediating role for rumination. Psychol Rep. 2010;106(1):3-12.

67. Andersen PA. Nonverbal Communication: Forms and Functions. Mountain View, CA: Mayfield Publishing Company; 1999.

68. Geerts E, Brüne M. Ethological approaches to psychiatric disorders: focus on depression and schizophrenia. Aust N Z J Psychiatry. 2009;43(11):1007-1015.

69. Holroyd S, Clayton AH. Measuring depression in the elderly: Which scale is best. Med Gen Med. 2000;2(4):430-554.

70. Boey KW. Cross-validation of a short form of the CES-D in Chinese elderly. Int J Geriatr Psychiatry. 1999;14(8):608-617.

71. Lewinsohn PM, Seeley JR, Roberts RE, Allen NB. Center for Epidemiologic Studies Depression Scale (CES-D) as a screening instrument for depression among community-residing older adults. Psychol Aging. 1997;12(2):277-287.

72. Antony MM. Assessment of anxiety and the anxiety disorders: an overview. Practitioner's Guide to Empirically Based Measures of Anxiety. Boston, MA: Springer; 2002:9-17.

73. Brink TL, Yesavage J, Lum O. Geriatric depression scale. EvidenceBased Diagnosis: A Handbook of Clinical Prediction Rules. New York, NY: Springer-Verlag; 2013;297-298.

74. Balsamo M, Carlucci L, Sergi MR, Klein Murdock K, Saggino A. The mediating role of early maladaptive schemas in the relation between co-rumination and depression in young adults. PLoS One. 2015; 10(10): $\mathrm{e} 0140177$.

75. Balsamo M, Carlucci L, Sergi MR, et al. Validazione della versione italiana del Co-Rumination Questionnaire: risultati preliminari. Psicoterapia Cognitiva e Comportamentale. 2016;22(1):13-34.

76. Carlucci L, D’Ambrosio I, Innamorati M, Saggino A, Balsamo M. Co-rumination, anxiety, and maladaptive cognitive schemas: when friendship can hurt. Psychol Res Behav Manag. 2018;11:133-144.

77. Moher D, Liberati A, Tetzlaff J, Altman DG. Preferred reporting items for systematic reviews and meta-analyses: the PRISMA statement. Ann Intern Med. 2009;151(4):264-269.

78. Zung WWK. A Self-Rating Depression Scale. Arch Gen Psychiatry. 1965;12(1):63-70.

79. Yesavage JA, Brink TL, Rose TL, Adey M. The Geriatric Depression Rating Scale: comparison with other self-report and psychiatric rating scales. In: Crook T, Ferris S, Bartus R, eds. Assessment in Geriatric Psychopharmacology. New Canaan, Conn: Mark Powley; 1983:153-167.

80. Brink TL, Yesavage JA, Lum O, Heersema PH, Adey M, Rose TL. Screening tests for geriatric depression. Clin Gerontol. 1982;1(1): 37-43.

81. Yesavage JA, Brink TL, Rose TL, et al. Development and validation of a geriatric depression screening scale: a preliminary report. $J$ Psychiatr Res. 1982;17(1):37-49.

82. Sheikh JI, Yesavage JA. 9/Geriatric depression scale (GDS) recent evidence and development of a shorter version. Clin Gerontol. 1986;5(1-2): $165-173$.

83. Beck AT, Steer RA, Brown GK. Beck depression inventory-II. San Antonio. 1996;78(2):490-498.
84. Radloff LS. The CES-D scale: a self-report depression scale for research in the general population. Appl Psychol Meas. 1977;1(3): 385-401.

85. Kohout FJ, Berkman LF, Evans DA, Cornoni-Huntley J. Two shorter forms of the CES-D depression symptoms index. $J$ Aging Health. 1993;5(2):179-193.

86. Andresen EM, Malmgren JA, Carter WB, Patrick DL. Screening for depression in well older adults: evaluation of short form of the CES-D. Prev Med. 1994;10:77-84.

87. van de Velde S, Levecque K, Bracke P. Measurement equivalence of the CES-D 8 in the general population in Belgium: a gender perspective. Arch Public Health. 2009;67(1):15.

88. Agrell B, Dehlin O. Comparison of six depression rating scales in geriatric stroke patients. Stroke. 1989;20(9):1190-1194.

89. Turner JA, Romano JM. Self-report screening measures for depression in chronic pain patients. J Clin Psychol. 1984;40(4):909-913.

90. Caroll B, Fielding J, Blashki T. Depression rating scales: a critical review. Arch Gen Psychiatry. 1973;28:361-366.

91. Gabrys JB, Peters K, Reliability PK. Reliability, Discriminant and predictive validity of the Zung Self-Rating Depression Scale. Psychol Rep. 1985;57(3_suppl):1091-1096.

92. Knight RG, Waal-Manning HJ, Spears GF. Some norms and reliability data for the State-Trait Anxiety Inventory and the Zung Self-Rating Depression Scale. Br J Clin Psychol. 1983;22(4):245-249.

93. Dunn VK, Sacco WP. Psychometric evaluation of the Geriatric Depression Scale and the Zung Self-Rating Depression Scale using an elderly community sample. Psychol Aging. 1989;4(1):125-126.

94. de Jonghe JFM, Baneke JJ. The Zung Self-Rating Depression Scale: a replication study on reliability, validity and prediction. Psychol Rep. 1989;64(3):833-834.

95. Dugan W, McDonald MV, Passik SD, Rosenfeld BD, Theobald D, Edgerton S. Use of the Zung Self-Rating Depression Scale in cancer patients: feasibility as a screening tool. Psychooncology. 1998;7(6):483-493.

96. Kivelä S-L, Pahkala K, Tervo R-R. Prevalence of depressive symptoms among an elderly Finnish population. Nordisk Psykiatrisk Tidsskrift. 1986;40(1):45-50.

97. McGarvey B, Gallagher D, Thompson L, Zelinski E. Reliability and factor structure of the Zung Self-Rating Depression Scale in 3 agegroups. Essence. 1982;5(2):141-152.

98. Berry JM, Storandt M, Coyne A. Age and sex differences in somatic complaints associated with depression. J Gerontol. 1984;39(4):465-467.

99. Zung WW, Richards CB, Short MJ. Self-rating depression scale in an outpatient clinic: further validation of the SDS. Arch Gen Psychiatry. 1965;13(6):508-515.

100. Hathaway SR, McKinley JC. The Minnesota Multiphasic Personality Inventory. Rev. ed, 2nd printing. Minneapolis, MN, US: University of Minnesota Press; 1943.

101. Zung WW. Factors influencing the self-rating depression scale. Arch Gen Psychiatry. 1967;16(5):543-547.

102. Zung WW. The depression status inventory: an adjunct to the selfrating depression scale. J Clin Psychol. 1972;28(4):539-543.

103. Biggs JT, Wylie LT, Ziegler VE. Validity of the Zung Self-Rating Depression Scale. Br J Psychiatry. 1978;132(4):381-385.

104. Hamilton M. A rating scale for depression. J Neurol Neurosurg Psychiatry. 1960;23(1):56.

105. Beck A, Ward C, Mendelson M, Mock J, Erbaugh J. An inventory for measuring. Arch Gen Psychiatry. 1961;4:561-571.

106. Beck AT, Beamesderfer A. Assessment of depression: the depression inventory. Psychological Measurements in Psychopharmacology. Vol 7. Paris: Karger Publishers. 1974:151-169.

107. Beck AT, Beck RW. Screening depressed patients in family practice: a rapid technic. Postgrad Med. 1972;52(6):81-85.

108. Kerner SA, Jacobs KW. Correlation between scores on the Beck Depression Inventory and the Zung Self-Rating Depression Scale. Psychol Rep. 1983;53(3):969-970. 
109. Åsberg M, Montgomery S, Perris C, Schalling D, Sedvall G. A comprehensive psychopathological rating scale. Acta Psychiatr Scand. 1978;57(S271):5-27.

110. Alexopoulos GS, Abrams RC, Young RC, Shamoian CA. Cornell scale for depression in dementia. Biol Psychiatry. 1988;23(3):271-284.

111. Sacco W. The Depression Symptom Checklist. Unpublished manuscript. University of South Florida, Department of Psychology. 1983.

112. Steuer J, Bank L, Olsen EJ, Depression JLF. Physical health and somatic complaints in the elderly a study of the Zung Self-Rating Depression Scale. J Gerontol. 1980;35(5):683-688.

113. Passik SD, Lundberg JC, Rosenfeld B, et al. Factor analysis of the Zung Self-Rating Depression Scale in a large ambulatory oncology sample. Psychosomatics. 2000;41(2):121-127.

114. Shafer AB. Meta-analysis of the factor structures of four depression questionnaires: Beck, CES-D, Hamilton, and Zung. J Clin Psychol. 2006;62(1):123-146.

115. Romera I, Delgado-Cohen H, Perez T, Caballero L, Gilaberte I. Factor analysis of the Zung Self-Rating Depression Scale in a large sample of patients with major depressive disorder in primary care. $B M C$ Psychiatry. 2008;8(1):4.

116. Blumenthal MD. Measuring depressive symptomatology in a general population. Arch Gen Psychiatry. 1975;32(8):971-978.

117. Harper RG, Kotik-Harper D, Kirby H. Psychometric assessment of depression in an elderly general medical population: over- or underassessment? J Nerv Ment Dis. 1990;178(2):113-119.

118. Watson LC, Lewis CL, Kistler CE, Amick HR, Boustani M. Can we trust depression screening instruments in healthy 'old-old' adults? Int J Geriatr Psychiatry. 2004;19(3):278-285.

119. Smarr KL, Keefer AL. Measures of depression and depressive symptoms: Beck Depression Inventory-II (BDI-II), Center for Epidemiologic Studies Depression Scale (CES-D), Geriatric Depression Scale (GDS), Hospital Anxiety and Depression Scale (HADS), and Patient Health Questionnaire-9 (PHQ-9). Arthritis Care Res. 2011;63(S11): 454-466.

120. Stiles PG, McGarrahan JF. The Geriatric Depression Scale: a comprehensive review. J Clin Geropsychol. 1998;4:90-110.

121. Rule BG, Harvey HZA, Dobbs AR. Reliability of the Geriatric Depression Scale for younger adults. Clin Gerontol. 1990;9(2):37-43.

122. Lesher E. Validation of the Geriatric Depression Scale among nursing home residents. Clin Gerontol. 1986;4(4):21-28.

123. Rapp SR, Parisi SA, Walsh DA, Wallace CE. Detecting depression in elderly medical inpatients. J Consult Clin Psychol. 1988;56(4):509.

124. Snyder AG, Stanley MA, Novy DM, Averill PM, Beck JG. Measures of depression in older adults with generalized anxiety disorder: A psychometric evaluation. Depress Anxiety. 2000;11(3):114-120.

125. Parmelee PA, Lawton MP, Katz IR. Psychometric properties of the Geriatric Depression Scale among the institutionalized aged. Psychol Assess. 1989;1(4):331.

126. Smalbrugge M, Jongenelis L, Pot AM, Beekman AT, Eefsting JA Screening for depression and assessing change in severity of depression. Is the Geriatric Depression Scale (30-, 15- and 8-item versions) useful for both purposes in nursing home patients? Aging Ment Health. 2008;12(2):244-248.

127. Lopez MN, Quan NM, Carvajal PM. A psychometric study of the Geriatric Depression Scale. Eur J Psychol Assess. 2010;26(1):55-60.

128. Folstein MF, Folstein SE, McHugh PR. "Mini-mental state": a practical method for grading the cognitive state of patients for the clinician. J Psychiatr Res. 1975;12(3):189-198.

129. Spitzer RL, Endicott J, Robins E. Research diagnostic criteria: rationale and reliability. Arch Gen Psychiatry. 1978;35(6):773-782.

130. Spielberger C, Gorsuch R, Lushene R, Vagg P, Jacobs G. Manual for the State-Trait Anxiety Inventory. Palo Alto, CA: Consulting Psychologists Press Inc.; 1983.

131. Frisch MB, Cornell J, Villanueva M, Retzlaff PJ. Clinical validation of the Quality of Life Inventory: a measure of satisfaction for use in treatment planning and outcome assessment. Psychol Assess. 1992;4: $92-101$.
132. Frisch MB. Quality of Life Inventory: Manual and Treatment Guide: National Computer Systems (NCS); Minneapolis, MN: 1994.

133. Feher EP, Larrabee GJ, Crook TH. Factors attenuating the validity of the Geriatric Depression Scale in a dementia population. J Am Geriatr Soc. 1992;40(9):906-909.

134. Korner ALL, Abelskov K, Gulmann N, Brodersen MA, WedervangJensen T, Marie Kjeldgaard MK. The Geriatic Depression Scale and the Cornell Scale for Depression in Dementia. A validity study. Nord J Psychiatry. 2006;60(5):360-364.

135. Wancata J, Alexandrowicz R, Marquart B, Weiss M, Friedrich F. The criterion validity of the Geriatric Depression Scale: a systematic review. Acta Psychiatr Scand. 2006;114(6):398-410.

136. Ott BR, Fogel BS. Measurement of depression in dementia: self vs clinician rating. Int J Geriatr Psychiatry. 1992;7(12):899-904.

137. Hyer L, Blount J. Concurrent and discriminant validities of the Geriatric Depression Scale with older psychiatric inpatients. Psychol Rep. 1984;54(2):611-616.

138. Lichtenberg PA, Steiner DA, Marcopulos BA, Tabscott JA. Comparison of the Hamilton Depression Rating Scale and the Geriatric Depression Scale: detection of depression in dementia patients. Psychol Rep. 1992;70(2):515-521.

139. Bentz BG, Hall JR. Assessment of depression in a geriatric inpatient cohort: a comparison of the BDI and GDS. Int J Clin Health Psychol. 2008;8(1):93-104.

140. Allen-Burge R, Storandt M, Kinscherf DA, Rubin EH. Sex differences in the sensitivity of two self-report depression scales in older depressed inpatients. Psychol Aging. 1994;9(3):443.

141. Sheikh JI, Yesavage JA, Brooks JO, et al. Proposed factor structure of the Geriatric Depression Scale. Int Psychogeriatr. 1991;3(1):23-28.

142. Salamero M, Marcos T. Factor study of the geriatric depression scale. Acta Psychiatr Scand. 1992;86(4):283-286.

143. Adams KB, Matto HC, Sanders S. Confirmatory factor analysis of the geriatric depression scale. Gerontologist. 2004;44(6):818-826.

144. Kim G, Decoster J, Huang C-H, Bryant AN. A meta-analysis of the factor structure of the Geriatric Depression Scale (GDS): the effects of language. Int Psychogeriatr. 2013;25(1):71-81.

145. Montorio I, Izal M. The Geriatric Depression Scale: a review of its development and utility. Int Psychogeriatr. 1996;8(1):103-112.

146. Olin JT, Schneider LS, Eaton EM, Zemansky MF, Pollock VE. The Geriatric Depression Scale and the Beck Depression Inventory as screening instruments in an older adult outpatient population. Psychol Assess. 1992;4(2):190.

147. Gallagher N, Wise G. A theoretical analysis of the properties of median filters. IEEE Trans Acoust. 1981;29(6):1136-1141.

148. Lesher EL, Berryhill JS. Validation of the geriatric depression scaleshort form among inpatients. J Clin Psychol. 1994;50(2):256-260.

149. Cwikel JRK. The short GDS: Evaluation in a heterogeneous multilingual population. Clin Gerontol. 1988;8:63-71.

150. Baker F, Miller CL. Screening a skilled nursing home population for depression. Topics in Geriatrics. 1991;4(4):218-221.

151. Burke WJ, Roccaforte WH, Wengel SP. The short form of the Geriatric Depression Scale: a comparison with the 30-item form. Top Geriatrics. 1991;4(3):173-178.

152. Pocklington C, Gilbody S, Manea L, McMillan D. The diagnostic accuracy of brief versions of the Geriatric Depression Scale: a systematic review and meta-analysis. Int J Geriatr Psychiatry. 2016;31(8):837-857.

153. Organization WH. The ICD-10 Classification of Mental and Behavioural Disorders. Diagnostic Criteria for Research. Geneva, NY; WHO; 1993.

154. van Marwijk H, Wallace P, de Bock GH, Hermans J, Kaptein AA, Mulder JD. Evaluation of the feasibility, reliability and diagnostic value of shortened versions of the geriatric depression scale. Br J Gen Pract. 1995;45(393):195-199.

155. Friedman B, Heisel MJ, Delavan RL. Psychometric properties of the 15-item geriatric depression scale in functionally impaired, cognitively intact, community-dwelling elderly primary care patients. $J$ Am Geriatr Soc. 2005;53(9):1570-1576. 
156. Malakouti SK, Fatollahi P, Mirabzadeh A, Salavati M, Reliability ZT. Validity and factor structure of the GDS-15 in Iranian elderly. Int $J$ Geriatr Psychiatry. 2006;21(6):588-593.

157. Montgomery SA, Åsberg M. A new depression scale designed to be sensitive to change. Br J Psychiatry. 1979;134(4):382-389.

158. Herrmann N, Mittmann N, Silver IL, et al. A validation study of the Geriatric Depression Scale short form. Int J Geriatr Psychiatry. 1996; 11(5):457-460.

159. Sheehan D, Lecrubier Y, Sheehan K, et al. The Mini-International Neuropsychiatric Interview (MINI): the development and validation of a structured diagnostic psychiatric interview for DSM-IV and ICD-10. J Clin Psychiatry. 1998;5934(59 Suppl 20):22-33.

160. Brown PJ, Woods CM, Storandt M. Model stability of the 15-item Geriatric Depression Scale across cognitive impairment and severe depression. Psychol Aging. 2007;22(2):372.

161. Mitchell AJ, Bird V, Rizzo M, Meader N. Diagnostic validity and added value of the Geriatric Depression Scale for depression in primary care: a meta-analysis of GDS30 and GDS15. J Affect Disord. 2010; 125(1):10-17.

162. Mitchell AJ, Bird V, Rizzo M, Meader N. Which version of the geriatric depression scale is most useful in medical settings and nursing homes? Diagnostic validity meta-analysis. Am J Geriatr Psychiatry. 2010;18(12):1066-1077.

163. Goldberg D. Use of the general health questionnaire in clinical work. Br Med J (Clin Res). 1986;293:1188-1189.

164. Mitchell AJ. Why doesn't depression treatment improve cancer survival? Lancet Psychiatry. 2018;5(4):289-291.

165. Alansari BM, Inventory BD. BDI-II items characteristics among undergraduate students of nineteen Islamic countries. Soc Behav Pers. 2005;33(7):675-684.

166. Campos RC, Gonçalves B. The Portuguese version of the beck depression inventory-II (BDI-II). Eur J Psychol Assess. 2011;27(4): 258-264.

167. Kapci EG, Uslu R, Turkcapar H, Karaoglan A. Beck Depression Inventory II: evaluation of the psychometric properties and cut-off points in a Turkish adult population. Depress Anxiety. 2008;25(10):104-110.

168. Ghassemzadeh H, Mojtabai R, Karamghadiri N, Ebrahimkhani N. Psychometric Properties of a Persian-Language Version of the Beck Depression Inventory. 2nd ed. Vol. 21;2005:185-192.

169. Gomes-Oliveira MH, Gorenstein C, Lotufo Neto F, Andrade LH, Wang YP. Validation of the Brazilian Portuguese version of the Beck Depression Inventory-II in a community sample. Rev Bras Psiquiatr. 2012;34(4):389-394.

170. Vanvoorhis CRW, Blumentritt TL. Psychometric properties of the Beck Depression Inventory-II in a clinically-identified sample of Mexican American adolescents. Journal of Child and Family Studies. 2007;16(6):789-798.

171. Wiebe JS, Penley JA. A psychometric comparison of the Beck Depression Inventory-II in English and Spanish. Psychol Assess. 2005;17(4):481.

172. Beck A, Steer R. Beck Anxiety Inventory Manual. San Antonio, TX: The Psychological Corporation; 1993.

173. Association AP. Diagnostic and Statistical Manual of Mental Disorders (DSM-IV). 4th ed. Washington: American Psychiatric Press; 1994.

174. Warmenhoven F, van Rijswijk E, Engels Y, et al. The Beck Depression Inventory (BDI-II) and a single screening question as screening tools for depressive disorder in Dutch advanced cancer patients. Support Care Cancer. 2012;20(2):319-324.

175. Gallagher D, Nies G, Thompson LW. Reliability of the Beck Depression Inventory with older adults. J Consult Clin Psychol. 1982;50(1):152.

176. Norris MP, Arnau RC, Bramson R, Meagher MW. The efficacy of somatic symptoms in assessing depression in older primary care patients. Clin Gerontol. 2004;27(1-2):43-57.

177. Segal DL, Coolidge FL, Cahill BS, O’Riley AA. Psychometric properties of the Beck Depression Inventory - II (BDI-II) among community-dwelling older adults. Behav Modif. 2008;32(1):3-20.
178. Rodríguez-Gómez JR, Dávila-Martínez MG, Collazo-Rodríguez LC. Factor structure of the Beck Depression Inventory-(BDI-II) with Puerto Rican elderly. P R Health Sci J. 2006;25(2):127-132.

179. Low GD, Hubley AM. Screening for depression after cardiac events using the Beck Depression Inventory-II and the Geriatric Depression Scale. Soc Indic Res. 2007;82(3):527.

180. Jefferson AL, Powers DV, Pope M. Beck Depression Inventory-II (BDI-II) and the geriatric depression scale (GDS) in older women. Clin Gerontol. 2001;22(3-4):3-12.

181. Steer RA, Rissmiller DJ, Beck AT. Use of Beck Depression Inventory-II with depressed geriatric inpatients. Behav Res Ther. 2000;38(3): 311-318.

182. Penley JA, Wiebe JS, Nwosu A. Psychometric properties of the Spanish Beck Depression Inventory-II in a medical sample. Psychol Assess. 2003;15(4):569.

183. Aş M, Sş I, Băban AS. Association of cognitive-emotional regulation strategies to depressive symptoms in type 2 diabetes patients. Rom J Intern Med. 2018;56(1):34-40.

184. Senior AC, Kunik ME, Rhoades HM, Novy DM, Wilson NL, Stanley MA. Utility of telephone assessments in an older adult population. Psychol Aging. 2007;22(2):392.

185. Warren WL. Revised Hamilton Rating Scale for Depression (RHRSD). Los Angeles, CA: Western Psychological Services; 1994.

186. Beck AT, Steer RA. BHS, Beck Hopelessness Scale. San Antonio, TX: Manual Psychological Corporation; 1988.

187. Beck AT, Kovacs M, Weissman A. Assessment of suicidal intention: the scale for suicide ideation. J Consult Clin Psychol. 1979; 47(2):343.

188. Coolidge FL. Coolidge Axis II Inventory Manual. Colorado Springs, CO: Author; 2004.

189. Ryff CD. Happiness is everything, or is it? Explorations on the meaning of psychological well-being. J Pers Soc Psychol. 1989; 57(6): 1069.

190. Cohen S, Kamarck T, Mermelstein R. A global measure of perceived stress. J Health Soc Behav. 1983;24(4):385-396.

191. Steer RA, Ball R, Ranieri WF, Beck AT. Further evidence for the construct validity of the Beck depression Inventory-II with psychiatric outpatients. Psychol Rep. 1997;80(2):443-446.

192. Picconi L, Balsamo M, Palumbo R, Fairfield B. Testing factor structure and measurement invariance across gender with Italian Geriatric Anxiety Scale. Front Psychol. 2018;9:1164.

193. At B, Steer R, Garbin M. Psychometric properties of the Beck Depression Inventory: twenty-five years of evaluation. Clin Psychol Rev. 1998;8:77-100.

194. Krell-Roesch J, Lowe VJ, Neureiter J, et al. Depressive and anxiety symptoms and cortical amyloid deposition among cognitively normal elderly persons: the Mayo Clinic Study of Aging. Int Psychogeriatr. 2018;30(2):245-251.

195. Arnau RC, Meagher MW, Norris MP, Bramson R. Psychometric evaluation of the Beck Depression Inventory-II with primary care medical patients. Health Psychol. 2001;20:112-119.

196. Hunt M, Auriemma J, Cashaw A. Self-report bias and underreporting of depression on the BDI-II. J Pers Assess. 2003;80:26-30.

197. Urbina S. Essentials of Psychological Testing. Hoboken, NJ: John Wiley \& Sons; 2014.

198. Edelstein BA, Woodhead EL, Segal DL, et al. Older adult psychological assessment: Current instrument status and related considerations. Clin Gerontol. 2007;31(3):1-35.

199. Wagle A, Ho L, Wagle S, Berrios G. Psychometric behaviour of BDI in Alzheimer's disease patients with depression. Int J Geriatr Psychiatry. 2000;15(1):63-69.

200. Brink T. Clinical Gerontology: A Guide to Assessment and Intervention: New York, NY: Routledge; 2014.

201. Radloff LS, Teri L. Use of the Center for Epidemiological Studies Depression Scale with older adults. Clin Gerontol. 1986;5(1-2): 119-136. 
202. Hertzog C, van Alstine J, Usala PD, Hultsch DF, Dixon R. Measurement properties of the Center for Epidemiological Studies Depression Scale (CES-D) in older populations. Psychol Assess. 1990;2(1):64.

203. O'Rourke N. Factor structure of the Center for Epidemiologic StudiesDepression Scale (CES-D) among older men and women who provide care to persons with dementia. Int J Test. 2005;5(3):265-277.

204. Miller TQ, Markides KS, Black SA. The factor structure of the CES-D in two surveys of elderly Mexican Americans. J Gerontol B Psychol Sci Soc Sci. 1997;52(5):S259-S269.

205. Noh S, Kaspar V, Chen X. Measuring depression in Korean immigrants: assessing validity of the translated Korean version of CES-D scale. Cross Cult Res. 1998;32(4):358-377.

206. Maqsood F, Flatt JD, Albert SM, et al. Correlates of self-reported depressive symptoms: a study of older persons of Punjab, Pakistan J Cross Cult Gerontol. 2013;28(1):65-74.

207. Chokkanathan S, Mohanty J. Factor structure of the CES-D scale among older adults in Chennai, India. Aging Ment Health. 2013;17(4): 517-525.

208. St John PD, Tyas SL, Montgomery PR. Depressive symptoms and frailty. Int J Geriatr Psychiatry. 2013;28(6):607-614.

209. Dozeman E, van Schaik DJ, van Marwijk HW, Stek ML, van der Horst HE, Beekman AT. The Center for Epidemiological Studies Depression Scale (CES-D) is an adequate screening instrument for depressive and anxiety disorders in a very old population living in residential homes. Int J Geriatr Psychiatry. 2011;26(3):239-246.

210. Malakouti SK, Pachana NA, Naji B, Kahani S, Reliability SM. Validity and factor structure of the CES-D in Iranian elderly. Asian J Psychiatr. 2015; 18:86-90.

211. Comstock GW, Helsing KJ. Symptoms of depression in two communities. Psychol Med. 1977;6(4):551-563.

212. Schein RL, Koenig HG. The Center for Epidemiological StudiesDepression (CES-D) Scale: assessment of depression in the medically ill elderly. Int J Geriatr Psychiatry. 1997;12(4):436-446.

213. Beekman AT, Deeg D, van Limbeek J, Braam AW, de Vries M, van Tilburg W. Brief communication: criterion validity of the Center for Epidemiologic Studies Depression scale (CES-D): results from a community-based sample of older subjects in the Netherlands. Psychol Med. 1997;27(1):231-235.

214. Lyness JM, Noel TK, Cox C, King DA, Conwell Y, Caine ED. Screening for depression in elderly primary care patients: a comparison of the Center for Epidemiologic Studies - Depression Scale and the Geriatric Depression Scale. Arch Intern Med. 1997;157(4):449-454.

215. Haringsma R, Engels G, Beekman A, Spinhoven P. The criterion validity of the Center for Epidemiological Studies Depression Scale (CES-D) in a sample of self-referred elders with depressive symptomatology. Int J Geriatr Psychiatry. 2004;19(6):558-563.

216. Irwin M, Artin KH, Oxman MN. Screening for depression in the older adult: criterion validity of the 10-item Center for Epidemiological Studies Depression Scale (CES-D). Arch Intern Med. 1999;159(15): 1701-1704.

217. Karim J, Weisz R, Bibi Z, ur Rehman S. Validation of the eight-item Center for Epidemiologic Studies Depression Scale (CES-D) among older adults. Curr Psychol. 2015;67(1):681-692.

218. Mohebbi M, Nguyen V, McNeil JJ, et al. Psychometric properties of a short form of the Center for Epidemiologic Studies Depression (CESD-10) scale for screening depressive symptoms in healthy community dwelling older adults. Gen Hosp Psychiatry. 2018;51:118-125.

219. Gellis ZD. Assessment of a brief CES-D measure for depression in homebound medically ill older adults. J Gerontol Soc Work. 2010;53(4):289-303.

220. Márquez-González M, Losada A, Fernández-Fernández V, Pachana NA. Psychometric properties of the Spanish version of the Geriatric Anxiety Inventory. Int Psychogeriatr. 2012;24(1):137-144.

221. Górkiewicz M, Chmiel I. The Center for Epidemiologic Studies Depression Scale (CES-D): is it suitable for use with older adults? Stud Logic Grammar Rhetoric. 2015;43(1):229-243.
222. Zhang B, Fokkema M, Cuijpers P, Li J, Smits N, Beekman A. Measurement invariance of the Center for Epidemiological Studies Depression Scale (CES-D) among Chinese and Dutch elderly. BMC Med Res Methodol. 2011;11(1):74.

223. Liu J, Wang Y, Wang X, Song R, Yi X. Reliability and validity of the Chinese version of geriatric depression scale among Chinese urban community-dwelling elderly population. Chinese J Clin Psychol. 2013;21(1):39-41.

224. Lue BH, Chen LJ, Wu SC, Health WS-C. Health, financial stresses, and life satisfaction affecting late-life depression among older adults: a nationwide, longitudinal survey in Taiwan. Arch Gerontol Geriatr. 2010;50 (Suppl 1):S34-S38.

225. Lee SW, Stewart SM, Byrne BM, et al. Factor structure of the Center for Epidemiological Studies Depression Scale in Hong Kong adolescents. J Pers Assess. 2008;90(2):175-184.

226. Seplaki CL, Goldman N, Weinstein M, Lin YH. Before and after the 1999 Chi-Chi earthquake: traumatic events and depressive symptoms in an older population. Soc Sci Med. 2006;62(12):3121-3132.

227. Miller WC, Anton HA, Townson AF. Measurement properties of the CESD scale among individuals with spinal cord injury. Spinal Cord. 2008;46(4):287-292.

228. Weiss RB, Aderka IM, Lee J, Beard C, Björgvinsson T. A comparison of three brief depression measures in an acute psychiatric population: CES-D-10, QIDS-SR, and DASS-21-DEP. J Psychopathol Behav Assess. 2015;37(2):217-230.

229. Zigmond AS, Snaith RP. The hospital anxiety and depression scale. Acta Psychiatr Scand. 1983;67(6):361-370.

230. Watson D, Clark LA. The mood and anxiety symptom questionnaire. Unpublished manuscript, University of Iowa, Department of Psychology, Iowa City; 1991.

231. Roberts KE, Hart TA, Eastwood JD. Factor structure and validity of the State-Trait Inventory for Cognitive and Somatic Anxiety. Psychol Assess. 2016;28(2):134.

232. Meyer TJ, Miller ML, Metzger RL, Borkovec TD. Development and validation of the Penn State Worry Questionnaire. Behav Res Ther. 1990;28(6):487-495.

233. Knight RG, Williams S, McGee R, Olaman S. Psychometric properties of the Centre for Epidemiologic Studies Depression Scale (CES-D) in a sample of women in middle life. Behav Res Ther. 1997;35(4): 373-380.

234. Knight RG, McMahon J, Skeaff CM, Green TJ. Normative data for persons over 65 on the Penn State Worry Questionnaire. NZJ Psychol. 2008;37(1):4-9.

235. Ree MJ, French D, Macleod C, Locke V. Distinguishing cognitive and somatic dimensions of state and trait anxiety: development and validation of the State-Trait Inventory for Cognitive and Somatic Anxiety (STICSA). Behav Cogn Psychoter. 2008;36(3):313-332.

236. Kuźmicz I, Brzostek T, Górkiewicz M. Barthel questionnaire as measurement tool for physical independence of older adults. Medical Studies. 2008;12:17-21.

237. Scott J, Huskisson EC. Graphic representation of pain. Pain. 1976;2(2): 175-184.

238. Bailey GA, Koepsell TD, Belcher DW. Reliability of two measures of life stress among outpatients at a Veterans Hospital. Am J Public Health. 1984;74(7):723-724.

239. Watson D, Clark LA, Tellegen A. Development and validation of brief measures of positive and negative affect: the PANAS scales. J Pers Soc Psychol. 1988;54(6):1063.

240. Diener E, Emmons RA, Larsen RJ, Griffin S. The satisfaction with life scale. J Pers Assess. 1985;49(1):71-75.

241. Lubben JE. Assessing social networks among elderly populations. Fam Commun Health. 1988;11(3):42-52.

242. Galasko D, Bennett D, Sano M, et al. An inventory to assess activities of daily living for clinical trials in Alzheimer's disease. Alzheimer Dis Assoc Disord. 1997;11:33-39. 
243. Missinne S, Vandeviver C, van de Velde S, Bracke P. Measurement equivalence of the CES-D 8 depression-scale among the ageing population in eleven European countries. Soc Sci Res. 2014;46: 38-47.

244. Foundation ES. The European Social Survey (ESS); 2012. Available from: http://www.esf.org/

245. Scheier MF, Carver CS, Bridges MW. Distinguishing optimism from neuroticism (and trait anxiety, self-mastery, and self-esteem): a reevaluation of the Life Orientation Test. J Pers Soc Psychol. 1994;67(6): 1063-1078.

246. Ilardi BC, Leone D, Kasser R, Ryan RM. Employee and supervisor ratings of motivation: main effects and discrepancies associated with job satisfaction and adjustment in a factory setting. J Appl Soc Psychol. 1994;23(21):1789-1805.

247. Rosenberg M. Society and the Adolescent Self-Image. Princeton University Press: Princeton.

248. Norman SB, Cissell SH, Means-Christensen AJ, Stein MB. Development and validation of an overall anxiety severity and impairment scale (OASIS). Depress Anxiety. 2006;23(4):245-249.

249. Boutin-Foster C. An item-level analysis of the Center for Epidemiologic Studies Depression Scale (CES-D) by race and ethnicity in patients with coronary artery disease. Int $J$ Geriatr Psychiatry. 2008;23(10):1034-1039.

250. Boyd JH, Weissman MM, Thompson WD, Myers JK. Screening for depression in a community sample. Understanding the discrepancies between depression symptom and diagnostic scales. Arch Gen Psychiatry. 1982;39(10):1195-1200.

251. Myers JK, Weissman MM. Use of a self-report symptom scale to detect depression in a community sample. Am J Psychiatry. 1980;137(9):1081-1084.

252. Roberts RE, Vernon SW. The Center for Epidemiologic Studies Depression Scale: its use in a community sample. Am J Psychiatry. 1983;140(1):41-46.

253. Melchior LA, Huba G, Brown VB, Reback CJ. A short depression index for women. Educ Psychol Meas. 1993;53(4):1117-1125.

254. Santor DA, Coyne JC. Shortening the CES-D to improve its ability to detect cases of depression. Psychol Assess. 1997;9(3):233.

255. Bracke P, Levecque K, Van de Velde S. The Psychometric Properties of the CES-D 8 Depression Inventory and the Estimation of CrossNational Differences in the True Prevalence of Depression. University of Leuven; 2008.

256. Baron EC, Davies T, Lund C. Validation of the 10-item Centre for Epidemiological Studies Depression Scale (CES-D-10) in Zulu, Xhosa and Afrikaans populations in South Africa. BMC Psychiatry. 2017;17(1):6.
257. Cheng ST, Chan AC, Fung HH. Factorial structure of a short version of the Center for Epidemiologic Studies Depression Scale. Int J Geriatr Psychiatry. 2006;21(4):333-336.

258. van de Velde $S$, Bracke P, Levecque K. Gender differences in depression in 23 European countries. Cross-national variation in the gender gap in depression. Soc Sci Med. 2010;71(2):305-313.

259. Conwell Y, Brent D. Suicide and aging. I: patterns of psychiatric diagnosis. Int Psychogeriatr. 1995;7(2):149-164.

260. Juurlink DN, Herrmann N, Szalai JP, Kopp A, Redelmeier DA. Medical illness and the risk of suicide in the elderly. Arch Intern Med. 2004;164(11):1179-1184.

261. National Institute for Clinical Excellence. Depression Management of depression in primary and secondary care. Clinical Guideline. 2004;23:3-15

262. Bolla-Wilson K, Bleecker ML. Absence of depression in elderly adults. J Gerontol. 1989;44(2):P53-P55.

263. Cairney J, Corna LM, Veldhuizen S, Herrmann N, Streiner DL. Comorbid depression and anxiety in later life: patterns of association, subjective well-being, and impairment. Am J Geriatr Psychiatry. 2008; 16(3):201-208.

264. McGivney SA, Mulvihill M, Taylor B. Validating the GDS depression screen in the nursing home. J Am Geriatr Soc. 1994;42(5):490-492.

265. Dozois DJA, Dobson KS. The Prevention of Anxiety and Depression: Theory, Research, and Practice. Whashington, DC: American Psychological Association; 2002.

266. Faravelli C, Albanesi G, Poli E. Assessment of depression: a comparison of rating scales. J Affect Disord. 1986;11(3):245-253.

267. Angst J, Azorin JM, Bowden CL, et al. Prevalence and characteristics of undiagnosed bipolar disorders in patients with a major depressive episode: the BRIDGE study. Arch Gen Psychiatry. 2011;68(8):791-799.

268. Manning JS, Haykal RF, Connor PD, Akiskal HS. On the nature of depressive and anxious states in a family practice setting: the high prevalence of bipolar II and related disorders in a cohort followed longitudinally. Compr Psychiatry. 1997;38(2):102-108.

269. Benazzi F. Prevalence of bipolar II disorder in outpatient depression: a 203-case study in private practice. J Affect Disord. 1997;43(2): 163-166.

270. Young AH. Bipolar disorder: diagnostic conundrums and associated comorbidities. J Clin Psychiatry. 2009;70(8):e26.

271. Innamorati M, Lester D, Balsamo M, et al. Factor validity of the Beck Hopelessness Scale in Italian medical patients. Journal of Psychopathology and Behavioral Assessment. 2014;36(2):300-307.

272. Balsamo M, Macchia A, Carlucci L, et al. Measurement of external shame: an inside view. Journal of Personality Assessment. 2015; 97(1):81-89.
Clinical Interventions in Aging

\section{Publish your work in this journal}

Clinical Interventions in Aging is an international, peer-reviewed journal focusing on evidence-based reports on the value or lack thereof of treatments intended to prevent or delay the onset of maladaptive correlates of aging in human beings. This journal is indexed on PubMed Central, MedLine,
Dovepress

CAS, Scopus and the Elsevier Bibliographic databases. The manuscript management system is completely online and includes a very quick and fair peer-review system, which is all easy to use. Visit http://www.dovepress. com/testimonials.php to read real quotes from published authors. 